\title{
Inflammatory, regulatory, and autophagy co-expression modules and hub genes underlie the peripheral immune response to human intracerebral hemorrhage
}

Marc Durocher ${ }^{1}$, Bradley P. Ander ${ }^{1}$, Glen Jickling ${ }^{1}$, Farah Hamade ${ }^{1}$, Heather Hull', Bodie Knepp ${ }^{1}$, Da Zhi Liu', Xinhua Zhan ${ }^{1}$, Anh Tran', Xiyuan Cheng ${ }^{1}$, Kwan Ng${ }^{1}$, Alan Yee', Frank R. Sharp ${ }^{1}$ and Boryana Stamova ${ }^{1,2^{*}}$ (D)

\begin{abstract}
Background: Intracerebral hemorrhage $(\mathrm{ICH})$ has a high morbidity and mortality. The peripheral immune system and cross-talk between peripheral blood and brain have been implicated in the ICH immune response. Thus, we delineated the gene networks associated with human ICH in the peripheral blood transcriptome. We also compared the differentially expressed genes in blood following $\mathrm{ICH}$ to a prior human study of perihematomal brain tissue.

Methods: We performed peripheral blood whole-transcriptome analysis of $\mathrm{ICH}$ and matched vascular risk factor control subjects $(n=66)$. Gene co-expression network analysis identified groups of co-expressed genes (modules) associated with $\mathrm{ICH}$ and their most interconnected genes (hubs). Mixed-effects regression identified differentially expressed genes in $\mathrm{ICH}$ compared to controls.

Results: Of seven ICH-associated modules, six were enriched with cell-specific genes: one neutrophil module, one neutrophil plus monocyte module, one T cell module, one Natural Killer cell module, and two erythroblast modules. The neutrophil/monocyte modules were enriched in inflammatory/immune pathways; the T cell module in T cell receptor signaling genes; and the Natural Killer cell module in genes regulating alternative splicing, epigenetic, and post-translational modifications. One erythroblast module was enriched in autophagy pathways implicated in experimental ICH, and NRF2 signaling implicated in hematoma clearance. Many hub genes or module members, such as IARS, mTOR, S1PR1, LCK, FYN, SKAP1, ITK, AMBRA1, NLRC4, IL6R, IL17RA, GAB2, MXD1, PIK3CD, NUMB, MAPK14, DDX24, EVL, TDP1, ATG3, WDFY3, GSK3B, STAT3, STX3, CSF3R, PIP4K2A, ANXA3, DGAT2, LRP10, FLOT2, ANK1, CR1, SLC4A1, and DYSF, have been implicated in neuroinflammation, cell death, transcriptional regulation, and some as experimental ICH therapeutic targets. Gene-level analysis revealed 1225 genes (FDR $p<0.05$, fold-change $>|1.2|$ ) have altered expression in $\mathrm{ICH}$ in peripheral blood. There was significant overlap of the 1225 genes with dysregulated genes in human perihematomal brain tissue $\left(p=7 \times 10^{-3}\right)$. Overlapping genes were enriched for neutrophil-specific genes $\left(p=6.4 \times 10^{-08}\right)$ involved in interleukin, neuroinflammation, apoptosis, and PPAR signaling.

(Continued on next page)
\end{abstract}

\footnotetext{
* Correspondence: bsstamova@ucdavis.edu

${ }^{1}$ Department of Neurology, University of California Davis School of Medicine, Sacramento, CA 95817, USA

${ }^{2}$ MIND Institute Biosciences Building, 2805 50th Street, Sacramento, CA 95817, USA
}

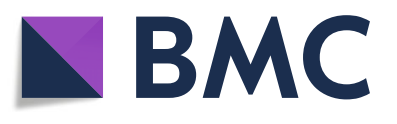

(c) The Author(s). 2019 Open Access This article is distributed under the terms of the Creative Commons Attribution 4.0 International License (http://creativecommons.org/licenses/by/4.0/), which permits unrestricted use, distribution, and reproduction in any medium, provided you give appropriate credit to the original author(s) and the source, provide a link to the Creative Commons license, and indicate if changes were made. The Creative Commons Public Domain Dedication waiver (http://creativecommons.org/publicdomain/zero/1.0/) applies to the data made available in this article, unless otherwise stated. 
(Continued from previous page)

Conclusions: This study delineates key processes underlying ICH pathophysiology, complements experimental ICH findings, and the hub genes significantly expand the list of novel ICH therapeutic targets. The overlap between blood and brain gene responses underscores the importance of examining blood-brain interactions in human $\mathrm{ICH}$.

Keywords: Intracerebral hemorrhage, ICH, NRF2, Autophagy, Hematoma, Hematoma clearance, Src kinase inhibitors, Gene expression, Co-expression networks, Gene networks

\section{Introduction}

Approximately 795,000 strokes occur in the USA each year [1]. Stroke remains a leading cause of death and disability $[2,3]$. Although primary non-traumatic intracerebral hemorrhage (ICH) only accounts for $10-15 \%$ of strokes [1, 4], its mortality rate of $59 \%$ at 1 year [4] is much higher than that for ischemic stroke (IS) (14\%) [5].

Many pre-clinical and a few clinical studies implicate neuroinflammation as contributing to neurological injury produced by $\mathrm{ICH}[3,6,7]$. Following $\mathrm{ICH}$, a complex cascade of local and systemic immune responses occurs leading to blood-brain barrier disruption, cerebral edema, and cell damage/death followed by hematoma removal and brain repair [7-11]. Since there is communication between the peripheral immune system and the central nervous system through afferent and efferent trafficking of cells and molecules, the peripheral immune system is a key driver of damage and repair following $\mathrm{ICH}[7,12,13]$. Peripheral leukocytic infiltration into the brain is seen early following ICH [7]. This involves chemokines, cytokines, matrix metalloproteinases (MMPs), and interactions between circulating leukocytes and vascular endothelial cells, with different cell types employing common as well as unique pathways [14]. Thus, it is important to study both the local and systemic immune response to human $\mathrm{ICH}$.

We examined the systemic peripheral immune response to human $\mathrm{ICH}$ and how it compares to the local human perihematomal brain tissue response. We investigated the peripheral blood gene co-expression networks and their most interconnected genes (hubs) following ICH, identified differential gene-level RNA expression and the potentially affected pathways, and compared the peripheral blood response to the one in previously published human peri-hematoma ICH brain [15]. The hub genes we identified have been implicated as major regulators of the immune response including the inflammasome, autophagy, and transcriptional and epigenetic regulation. Some of the hub genes have also been successfully tested in animal ICH models. Notably, there was a significant overlap between genes differentially expressed in this human ICH peripheral blood study compared to a prior human study of perihematomal brain tissue [15]. These findings will further our understanding of the biological processes occurring following $\mathrm{ICH}$, as well as provide human data confirming targets that have been tested or will be tested in animal ICH models. The findings also highlight candidate genes that influence major processes underlying the response to ICH and parallel responding genes/pathways in blood and brain, underscoring the importance of further studies of the peripheral blood-brain immune communication.

\section{Materials and methods}

\section{Study subjects}

Sixty-six male (M) and female (F) subjects with intracerebral hemorrhage (ICH, $n=33,24 \mathrm{M} / 9 \mathrm{~F})$ and vascular risk factor (VRF)-matched control subjects (CTRL, $n=$ 33, 24 M/9F) were recruited from the Universities of California at Davis and San Francisco as well as the University of Alberta, Canada. Procedures were approved by the IRBs at participating universities and written informed consent was obtained from participants or their proxy. ICH was diagnosed by board-certified neurologists based upon histories, exams, and magnetic resonance imaging (MRI) and/or computed tomographic (CT) brain scan [16]. Subjects were matched for age, race, sex, and VRFs, which included hypertension, diabetes mellitus, hyperlipidemia, and smoking status. Exclusion criteria were previous stroke (for CTRLs) and ischemic stroke with hemorrhagic transformation.

\section{Blood collection, RNA isolation}

Blood was collected in PAXgene tubes and RNA isolated as previously described $[17,18]$. There was a single blood draw per subject. Time after symptom onset for $\mathrm{ICH}$ varied from 4.2 to $124.3 \mathrm{~h}$.

\section{Arrays and processing}

RNA was processed on the GeneChip Human Transcriptome Array (HTA) 2.0 (Affymetrix, Santa Clara, CA) which examines the coding and non-coding transcriptome. Raw expression values for each gene were saved in Affymetrix.CEL and Affymetrix.DAT files. Using Affymetrix Power Tools (APT), the. CEL transformer applied GC correction (GCCN) and single space transformation (SST) to the HTA.CEL files. GCCN-SST transformations were conducted through a command line using APT 1.18.0 in "batch" mode. GCCN-SST transformed .CEL files were uploaded into Partek Flow software (Partek Inc., St. Louis, MO) and probe sets 
mapped to the Human Genome hg19 using the STAR 2.4.1d aligner. Nominal read coverage depth was defined as 30 million and default mapping parameters were used. RPKM normalization was performed.

\section{Weighted gene co-expression network construction and analysis}

The 56,638 genes (mRNA and ncRNA) present in $\mathrm{ICH}$ and CTRL data were filtered by removing genes with a maximum expression across all samples of $<5$, leaving 29,513 genes. Then, genes with expression $<3$ in greater than $50 \%$ of the male and female samples across all groups were removed, leaving 21,175 genes. This was done to remove potential outliers, reduce noise, decrease sex bias due to an uneven number of males and females in the data, and focus analyses on the most robust correlations. Data were then imported into $\mathrm{R}$ and the function goodSamplesGenes within the WGCNA package used to identify any missing values or zero-variance genes to be removed from the sample. The CTRL and $\mathrm{ICH}$ data were then processed in R using WGCNA [19].

WGCNA identified Pearson correlations throughout the data to develop modules of co-expressed genes. An approximate scale-free topology was depicted by the data, as is expected of gene co-expression networks [20]. To maximize strong correlations between genes, we assigned a soft-thresholding power $\beta=8$ since it was the lowest $\beta$ with the highest $R^{2}$ value that passed the 0.8 threshold (Additional file 1: Figure S1). Due to the large number of genes being processed, we set the minimum module size to 100 genes. Rather than using a static cut-off during module construction, we utilized the cutreeDynamic function to form modules because of its ability to identify nested modules within complex dendrograms [21]. Additional parameters within cutreeDynamic included method = "tree" and deepSplit = FALSE. To focus on genes of likely greatest importance in $\mathrm{ICH}$, we identified those with the top 5\% highest membership to their respective module [22]. These hub genes are highly interconnected within the module and their interconnectivity was quantified by kIN-the gene's intramodular connectivity [23]. Significant modules with respect to diagnosis $(\mathrm{ICH}, \mathrm{CTRL})$ were extracted $(p(\mathrm{Dx})$ $<0.05)$ for additional processing.

\section{Differential gene expression}

Differentially expressed genes were derived using Partek Genomics Suite 7.17 software (Partek Inc., St. Louis, $\mathrm{MO})$ on the complete post-filtered dataset of 21,175 genes. A three-way ANCOVA model with REML (restricted maximum likelihood) and the factors diagnosis, scan date, sex, age, time, and an interaction between diagnosis and sex was used. Genes passing a FDR (false-discovery rate) $p$ value $<0.05$ and a fold change (FC) $>|1.2|$ for ICH vs CTRL were considered significant.

\section{Cell-specific gene involvement}

To identify modules of co-expressed genes enriched with blood cell type-specific genes, we overlapped the gene list of each module with lists of blood cell type-specific genes [24, 25]. We calculated significant overlaps of genes using hypergeometric probability testing with the $\mathrm{R}$ function phyper. Those with a $p<0.05$ were deemed significant.

\section{Pathway and gene ontology analyses}

Hub genes and modules significant for diagnosis were further analyzed with ingenuity pathway analysis (IPA) [26] and the DAVID Bioinformatics Database (DAVID 6.8) [27]. Module genes were input into IPA to map them to molecular functions, associated diseases, and canonical pathways [28] using Fisher's exact test $p<0.05$ and a multiple-comparison correction via the BenjaminiHochberg procedure (adjusted $p<0.05$ ). The same lists of module genes were input into DAVID for gene ontology (GO) analysis (EASE adjusted Fisher's exact test $p<$ 0.05).

\section{Network visualization and hub gene identification}

The $\mathrm{R}$ function within WGCNA visantPrepOverall generated a list of intramodular gene connections that were imported into VisANT to visualize the networks [29, 30]. To better capture hub gene connectivity, parameters modified within the visantPrepOverall function were numint $=10,000$ and signed $=$ FALSE. After importing the data into VisANT, the minimum weight cutoff was adjusted to display a visually distinguishable number of connections. The lengths and colors of the edges (connections) in the images are arbitrary. Networks were created with VisANT for modules deemed significant with $p(\mathrm{Dx})<0.05$ and for significant hub gene networks within them.

\section{Results}

Demographic and clinical characteristics

Subjects' demographic and clinical characteristics are listed in Additional file 2: Table S1 [18]. There were no significant differences in hypertension, diabetes mellitus, hyperlipidemia, or smoking for ICH compared to CTRL subjects. Time since ICH to blood draw was $57.3 \pm$ $30.6 \mathrm{~h}$ ( \pm standard deviation). The mean age of ICH subjects was $62 \pm 14.3$ years ( \pm standard deviation) and was not significantly different from $63.5 \pm 13.1$ years for CTRL. 


\section{WGCNA: ICH and CTRL analysis}

\section{Module assignments}

Analysis of the 66 samples (33 CTRL and $33 \mathrm{ICH}$ ) for 21,175 genes identified 41 modules of co-expressed genes. Modules ranged in size from 2416 (turquoise) to 114 genes (lightsteelblue1). A gene dendrogram and their modules are shown in Fig. 1a. A dendrogram of the module eigengenes (representative of the overall gene expression within that module) is shown in Fig. 1b. Genes and their module assignments are listed.

in Additional file 2: Table S2. Of the 41 modules, 7 showed a significant difference between ICH and CTRL groups with $p(\mathrm{Dx})<0.05$ (cyan, darkolive green, greenyellow, magenta, red, sienna3, and tan) (marked with asterisks in Fig. 1a and colored in module-corresponding colors in Fig. 1b).

\section{Cell type involvement}

We then compared the genes in the $\mathrm{ICH}$-associated modules $(p(\mathrm{Dx})<0.05)$ to genes reported to be expressed in normal human erythroblasts, megakaryocytes, B cells, cytotoxic and helper T cells, natural killer cells, granulocytes, or monocytes $[24,25]$. There was significant overlap/enrichment in six of the seven ICH modules (Fig. 1a). Cyan and sienna3 were enriched for erythroblast-specific genes $\left(p=4.9 \times 10^{-10}\right.$ and $p<1 \times$ $10^{-16}$, respectively); $\tan$-with $\mathrm{CD} 6 \mathrm{~b}^{+} /$neutrophil-specific genes $\left(p<1 \times 10^{-16}\right)$; and greenyellow-with $\mathrm{CD} 14^{+} /$ monocyte and $\mathrm{CD} 66 \mathrm{~b}^{+} /$neutrophil-specific genes $(p=$ $2.9 \times 10^{-06}$ and $p<1 \times 10^{-16}$, respectively). Magenta was enriched with genes selectively expressed in T cells $(p<$ $\left.1 \times 10^{-16}\right)$, and red with $\mathrm{CD} 56^{+} /$natural killer cell-specific genes $\left(p=1.8 \times 10^{-2}\right)$. Lists of these genes and their modules are in Additional file 2: Table S3.

\section{Central intramodular hub genes}

Hub genes may be important targets for treating $\mathrm{ICH}$. A list of hub genes for each module is in Additional file 2: Table S4 and the canonical pathways for those hub genes are listed in Additional file 2: Table S5. The VisANT networks of the $\mathrm{ICH}$-associated modules, including their hub genes and the biological processes that are overrepresented in each module are depicted in Figs. 2, 3, and 4. Figures 2a, c, 3a, c, and 4a, c, d show the networks of the seven $\mathrm{ICH}$ diagnosis-significant modules, where the enlarged, labeled, and colored (non-gray) nodes are the module's hub genes. Not all genes and connections are displayed since inclusion of too many generated an incomprehensible image.

The most statistically significant hub genes included isoleucyl-TRNA synthetase (IARS) (Fig. 3a; Additional file 1: Figure S2); sphingosine-1 phosphate receptor 1 (S1PR1) (Additional file 1: Figure S3); T cell receptor alpha joining 36 (TRAJ36) (Fig. 3a); proto-oncogene, Src family tyrosine kinase (LCK) (Fig. 5); IL2 inducible T cell kinase (ITK) (Additional file 1: Figure S4); mediator complex subunit 1 (MED1), mediator complex subunit 14 (MED14), small nuclear ribonucleoprotein U5 subunit 200 (SNRNP200) (Fig. 6), mechanistic target of rapamycin kinase (mTOR), autophagy nd beclin 1 regulator 1 (AMBRA1) (mTOR and

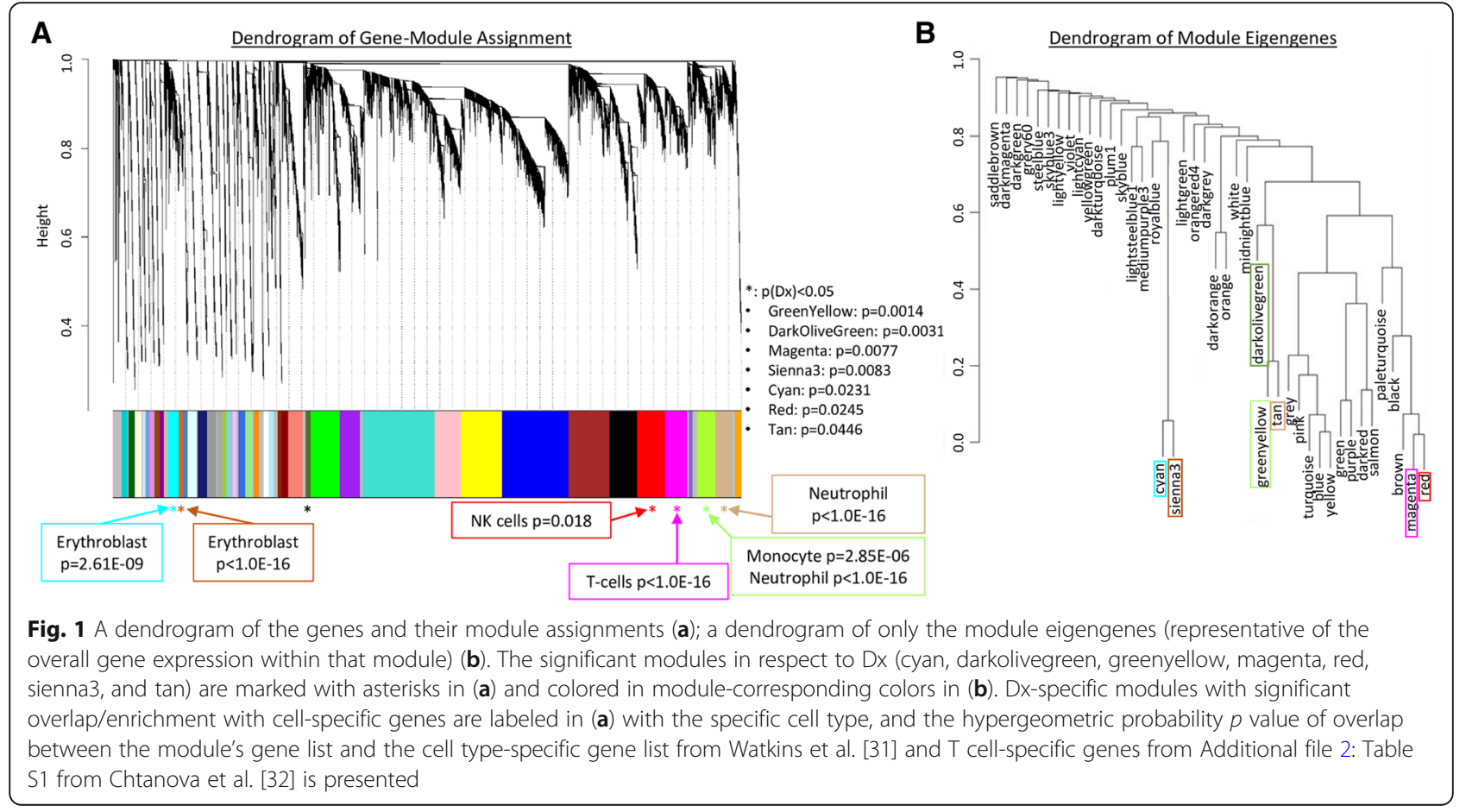



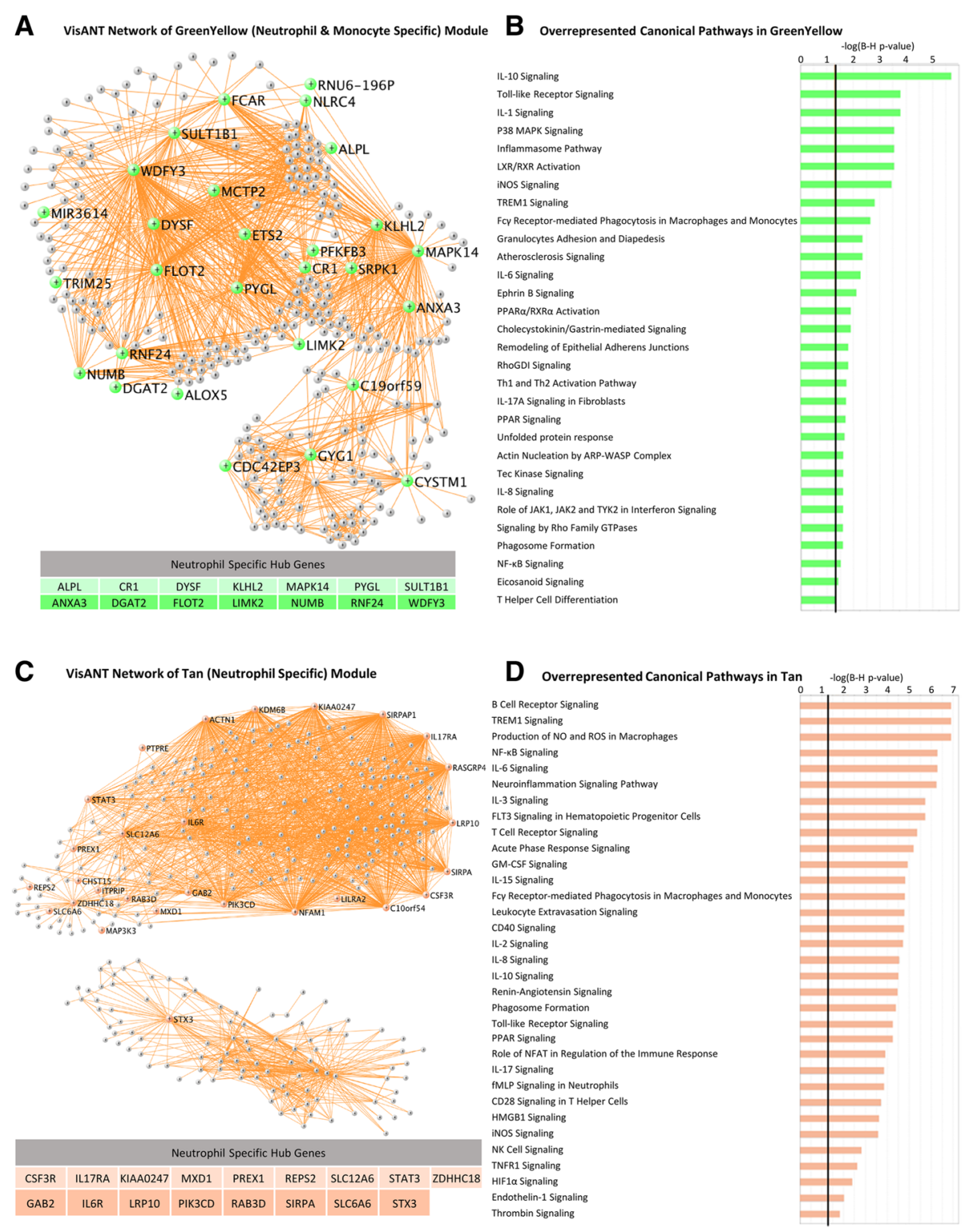

Fig. 2 Greenyellow module. a VisANT Network of greenyellow (neutrophil- and monocyte- specific) module. The hub genes are colored in greenyellow. Neutrophil-specific hub genes are listed below. b Overrepresented canonical pathways in greenyellow (IPA analysis, Benjamini-Hochberg (B-H) corrected $p<0.05)$. $X$-axis: negative $\log _{10}$-transformed $p$-value for significance for enrichment in specific IPA pathways. Pathways higher than the black vertical line $\left(-\log _{10}(\mathrm{~B}-\mathrm{H} p)\right)>1.3$ (which corresponds to $\left.p(\mathrm{~B}-\mathrm{H} p)<0.05\right)$ are significant. $\mathbf{c}$, $\mathbf{d}$ Tan module. Hub genes are colored in tan

AMBRA1 networks) (Additional file 1: Figures S5 and S6); NLR family CARD domain containing 4 (NLRC4), WD repeat and FYVE domain containing 3 (WDFY3), microRNA 3614 (miR3614) (Additional file 1: Figures S7, S8, and S9); autophagy related 3 (ATG3) (Additional file 1: Figure S10); solute carrier family 4 member 1 (Diego blood group) (SLC4A1), ankyrin 1 (ANK1) (Additional file 1: Figures S11 and S12); phosphatidylinositol-5-phosphate 4-kinase type 2 alpha (PIP4K2A) (Additional file 1: Figure S13); colony stimulating factor 3 receptor (CSF3R) (Additional file 1: Figure S14); and signal transducer and activator of transcription 3 (STAT3) (Fig. 7). The $p$ values for diagnosis for the hub genes in all modules are in Additional file 2: Table S6a.

There were two non-coding RNA hub genes: SNRNP200 (Fig. 6) and microRNA miR3614 (Additional file 1: Figure S9). Of the modules with a significant association to $\mathrm{ICH}$ diagnosis, DarkOliveGreen (the only module not associated with a specific cell type) was the only module that also showed an association to the time since stroke onset. The $p$ values for time-since-event for all modules are shown in Additional file 2: Table S6b. 


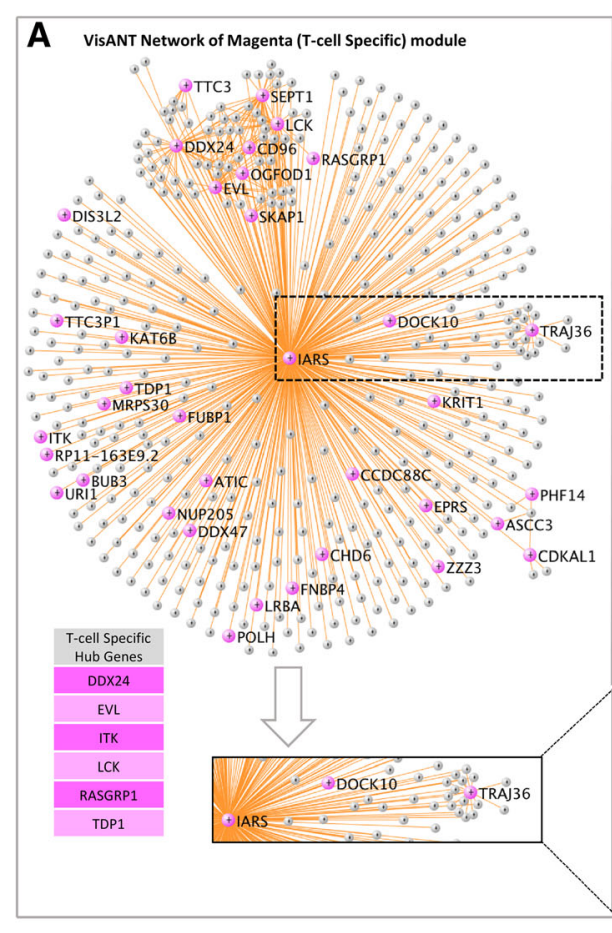

B Overrepresented Canonical Pathways in Magenta

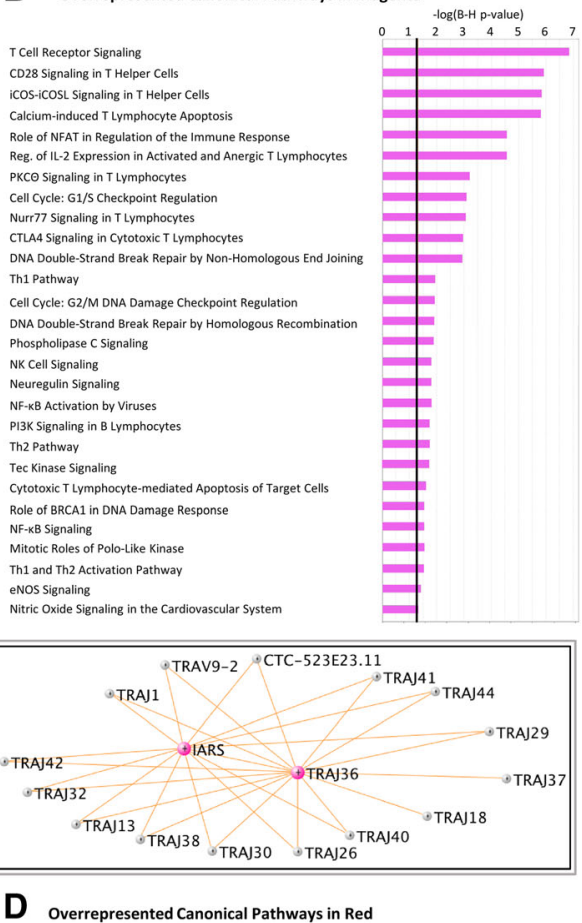

C VisANT Network of Red (NK Cell Specific) Module

D overrepresented
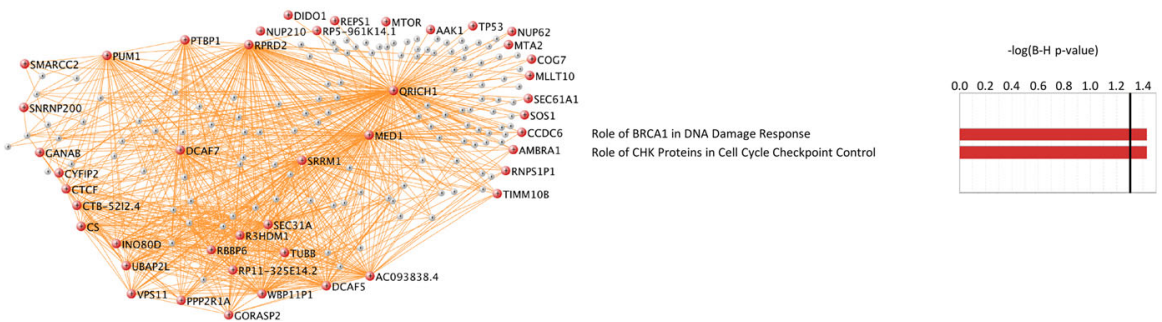

Fig. 3 a, b VisANT network of magenta (T cell specific) module. The Hub genes are colored in magenta. T cell specific hub genes are listed below. $\mathbf{b}$ Overrepresented canonical pathways in magenta (IPA analysis, B-H corrected $p<0.05$ ). X-axis: negative $\log _{10}$-transformed $p$ value for significance for enrichment in specific IPA pathways. Pathways higher than the black vertical line (-Log $\left.{ }_{10}(\mathrm{~B}-\mathrm{H} p)\right)>1.3$ (which corresponds to $p(\mathrm{~B}-$ $\mathrm{H} p$ p) 0.05$)$ are significant. $\mathbf{c}$, d Red module. Hub genes are colored in red

The hub genes for each module differed by cell type and function. Notably, 14 out of 31 of the hub genes in the greenyellow module were neutrophil-specific (Fig. 2a). More than half of the hub genes in the tan module were neutrophil-specific (17 out of the 28) (Fig. 2c). Six hub genes in magenta (Fig. 3a) were T cell specific. Three hub genes in sienna3 (erythroblast module) were erythroblast-specific (Fig. 4c). Table 1 shows all hub genes in the ICH-significant modules; Table 2 shows three representative hub genes for each module and their relevant functions.

\section{Pathway analyses}

A list of pathways associated with each module is in Additional file 2: Table S7. Selected pathways in the $\mathrm{ICH}$-associated modules are shown in Figs. $2 \mathrm{~b}, \mathrm{~d}, 3 \mathrm{~b}, \mathrm{~d}$, and $4 \mathrm{~b}$. The greenyellow module (neutrophil/monocyte module) included toll-like receptor (TLR), inflammasome, and PPAR signaling which are all involved in neuroinflammation (Fig. 2b). The tan module (neutrophil module) included leukocyte extravasation signaling (Additional file 1: Figure S15), several interleukin-signaling pathways, $\mathrm{T}$ and $\mathrm{B}$ cell receptor signaling, apoptosis pathways, NF- $\mathrm{kB}$ signaling, and PPAR signaling. Tan module functions included renin-angiotensin and endothelin-1-signaling related to vasoconstriction/vasodilation; and coagulation pathways such as thrombin signaling (Fig. 2d).

The magenta module was mainly associated with $\mathrm{T}$ cell receptor signaling (Additional file 1: Figure S16) and pathways involving $\mathrm{T}$ lymphocytes (Fig. $3 \mathrm{~b}$ ) (CD28 signaling in $\mathrm{T}$ helper cells, iCOS-iCOSL signaling in $\mathrm{T}$ helper cells, Th1 and Th2 pathways, calcium-induced $\mathrm{T}$ lymphocyte apoptosis, PKCO, and Nur77 signaling in T 

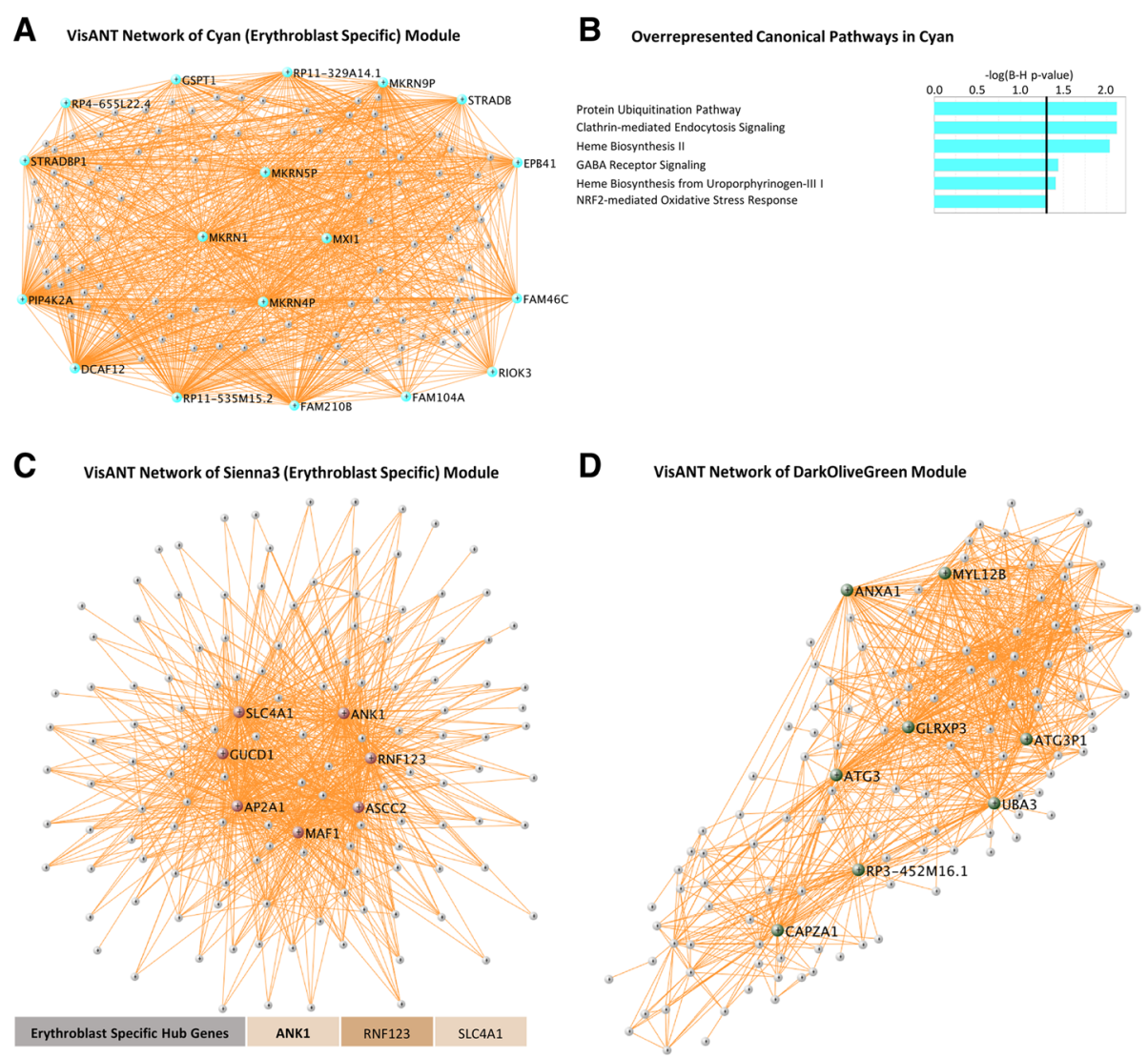

Sienna3 and DarkOliveGreen Modules do not have significant pathways that pass BH corrected p>0.05 in IPA

Fig. 4 a, $\mathbf{b}$ VisANT network of cyan (erythroblast-specific) module. The hub genes are colored in cyan. b Overrepresented canonical pathways in cyan (IPA analysis, B-H corrected $p<0.05$ ). X-axis: negative $\log _{10}$-transformed $p$ value for significance for enrichment in specific IPA pathways. Pathways higher than the black vertical line $\left(-\log _{10}(\mathrm{~B}-\mathrm{H} p)\right)>1.3$ (which corresponds to $p(\mathrm{~B}-\mathrm{H} p)<0.05$ ) are significant. $\mathbf{c}$ VisANT network of sienna3 module. Hub genes are colored in sienna3. No IPA pathways passed B-H corrected $p<0.05$. d VisANT network of darkolivegreen module. Hub genes were colored in dark olive green. No IPA pathways passed B-H corrected $p<0.05$

lymphocytes). The red module (natural killer cell module) was overrepresented with genes involved in DNA repair and cell cycle regulation (Fig. 3d). The cyan module (erythroblast module) was associated with the NRF2-mediated oxidative stress response, protein ubiquitination, and clathrin-mediated endocytosis, which are all pathways implicated in hematoma clearance following ICH [31-33], as well as heme biosynthesis pathways (Fig. 4b).

The statistically significant processes $(p<0.05)$ using gene ontology (DAVID functional annotation tool) are shown in Additional file 2: Table S8. The top 3 in each module are listed in Fig. 8. Some of the processes not mentioned above included apoptosis and autophagy (greenyellow), insulin receptor signaling (darkolivegreen), amino acid transport and Wnt signaling (sienna3), protein ubiquitination and macroautophagy and mitophagy (cyan), mRNA splicing and protein sumoylation (red), and MAPKK and JAK-STAT signaling (tan).
Gene-level expression in blood compared to perihematomal brain

Of the 21,175 genes examined in this study, 1225 showed differential gene-level expression between ICH and CTRL (FDR $p<0.05, \mathrm{FC}>|1.2|$; Additional file 2: Table S9a). There were 63 hub genes (Table 1) from the 7 modules associated with ICH (Additional file 2: Table S9b). The most significant pathways associated with the 1225 genes were $\mathrm{T}$ and $\mathrm{B}$ cell receptor signaling, Th1 and Th2 activation, neuroinflammation, and IL-1, $-2,-6,-8,-10$, and -12 signaling (Additional file 2: Table S9c). The 1225 gene list was enriched with genes associated with neutrophils $(p<$ $\left.1 \times 10^{-16}\right)$ and T cells $\left(p=1.9 \times 10^{-3}\right)$ (Additional file 2: Table S9d). There was neutrophil enrichment in greenyellow and tan modules $\left(p=5.6 \times 10^{-13}\right.$ and $p=4.6 \times 10^{-4}$, respectively), and $\mathrm{T}$ cell enrichment in magenta $(p=3.1 \times$ $10^{-06}$ ) (Additional file 2: Table S9e).

By assessing gene-level expression in blood of $\mathrm{ICH}$ subjects, we were able to compare our study to another 


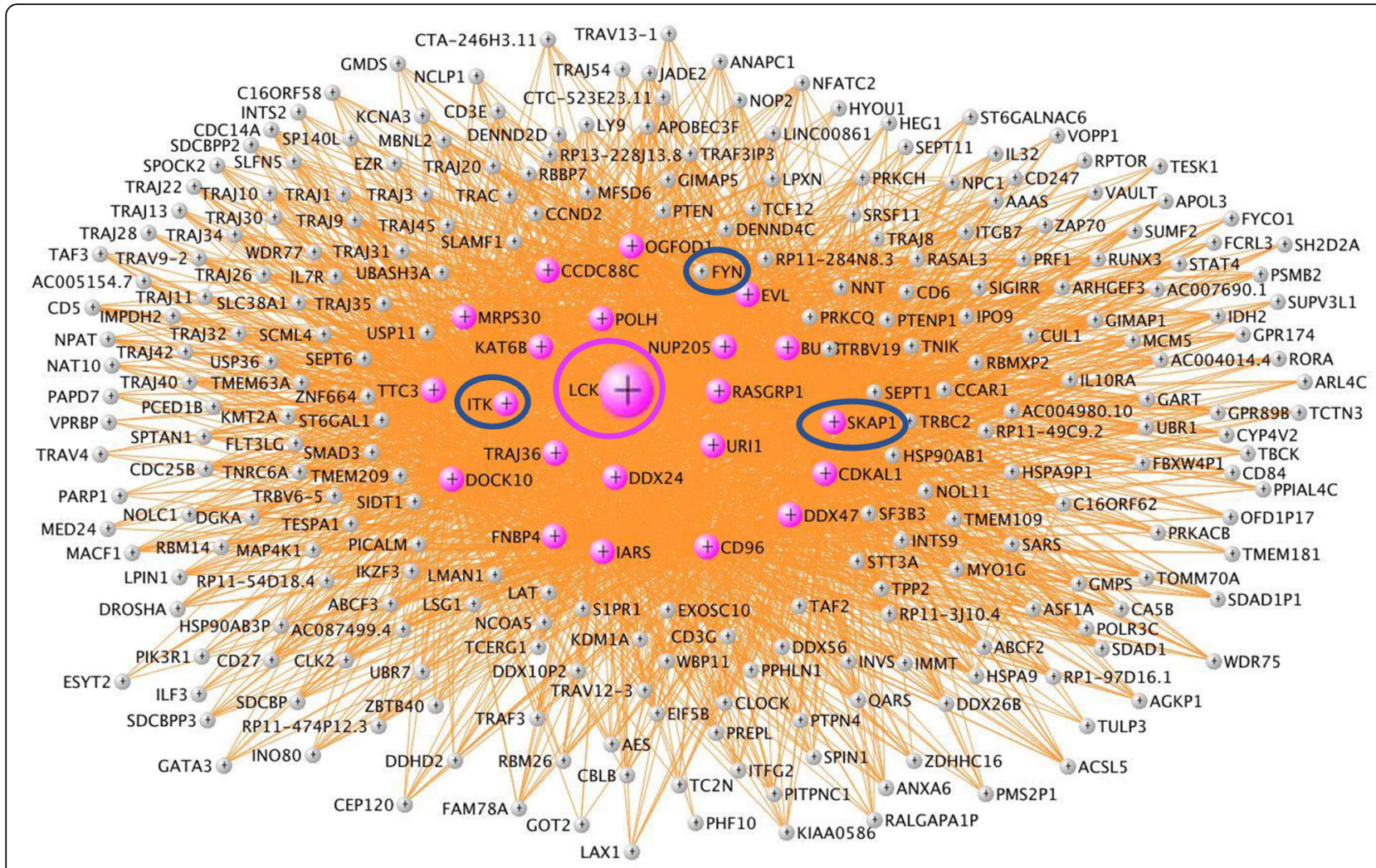

Fig. 5 LCK network in the magenta module. Genes colored in magenta are hub genes. Note other Src kinases (like FYN and ITK) and Src kinaseassociated protein (SKAP1) are circled

that examined human perihematomal brain tissue [15]. Forty-six of our blood-derived differentially expressed genes (DEGs) overlapped with the list of 534 DEGs from the brain ICH study $(p=0.007$; Additional file 2: Table S9f) (Fig. 9). The 46 DEGs showed enrichment for neutrophil-specific genes $\left(6.4 \times 10^{-08}\right.$; Additional file 2: Table S9g). The 46 genes were involved in interleukin (1, 6 , 8, and 10) signaling, neuroinflammation, apoptosis, and PPAR signaling (Fisher's Exact $p<0.05$; Additional file 2: Table S9h).

\section{Discussion}

Seven modules of co-expressed genes were associated with $\mathrm{ICH}$. Six were enriched in genes predominantly expressed in specific cell types suggesting cell-specific coordination of the peripheral immune response to $\mathrm{ICH}$. This confirms many experimental studies of a complex immune response to $\mathrm{ICH}[7,34]$. The identified hub genes are biologically relevant, involved in major pathways including immune, autophagy and transcriptional, post-transcriptional, and epigenetic regulation and hematoma clearance. A number of these pathways have also been reported in experimental ICH studies [7, 34]. The data highlights the utility of systems-level approaches to studying human $\mathrm{ICH}$.

\section{Neutrophil and monocyte modules (greenyellow and tan modules)}

Neutrophils are among the first peripheral blood cell type to infiltrate perihematomal brain and vessels and the hematoma itself following ICH [35]. Neutrophils contribute to blood-brain barrier (BBB) breakdown, chemoattraction, activation of resident microglia, and brain injury at early times following ICH [36]. Later, IL-27 shifts neutrophils from producing pro-inflammatory/ cytotoxic products to production of beneficial iron-scavenging molecules like lactoferrin [37]. IL-27 and lactoferrin reduced edema, enhanced hematoma clearance, and improved neurological outcomes in experimental ICH [37]. Peripheral monocytes also enter the brain after ICH and eventually outnumber neutrophils [7]. They also appear to have adverse effects early, but then contribute to tissue repair and hematoma phagocytosis later after ICH [7].

Our data revealed two modules enriched in neutrophil-specific genes and one of these was also enriched in monocyte-specific genes. The greenyellow (neutrophil and monocyte) module included IL-6, IL-8, and IL-10 signaling; inflammasome pathway and phagosome formation; toll-like receptor (TLR) signaling; NF-kB and PPAR signaling; and processes involved in 


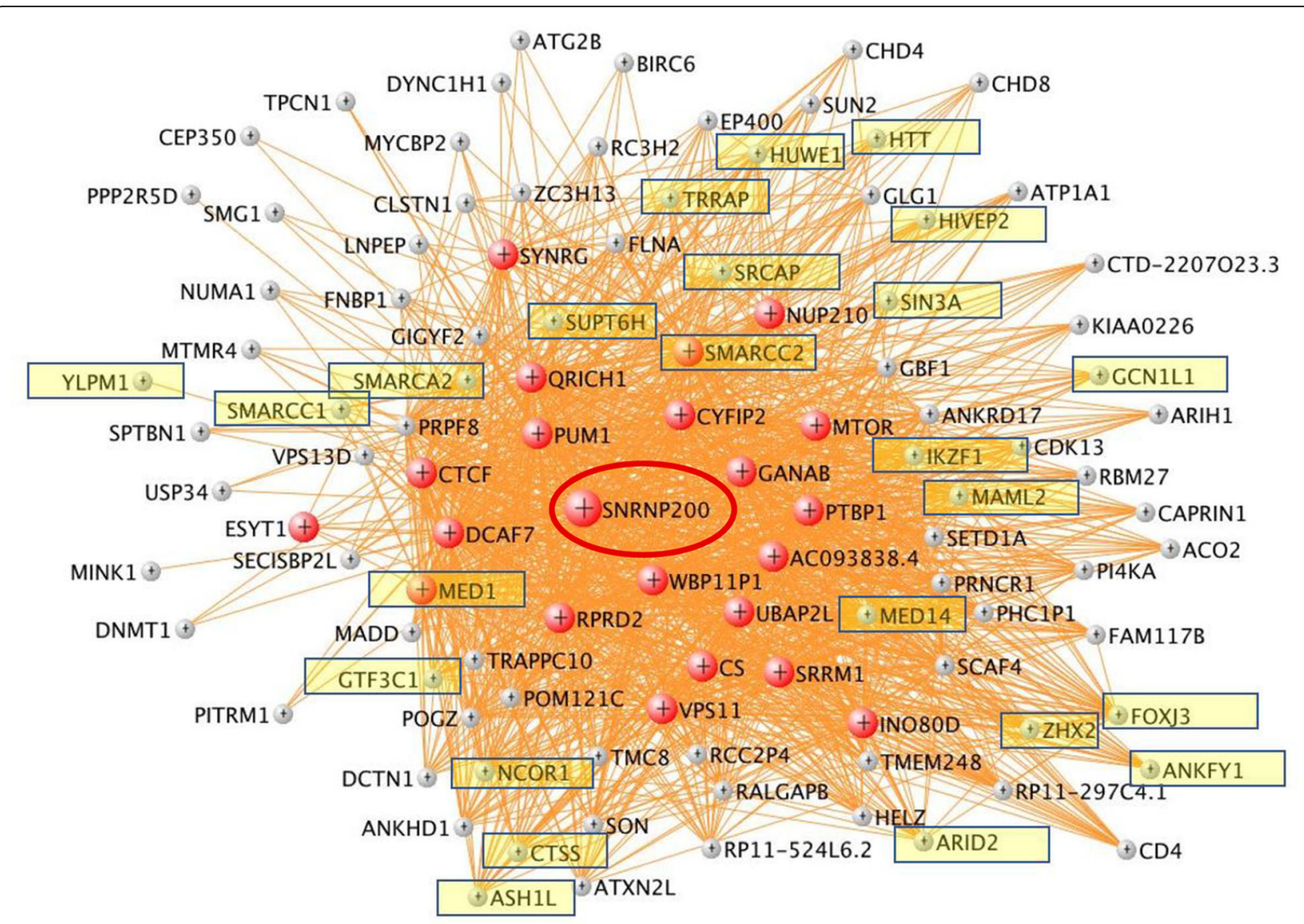

Fig. 6 SNRNP200 network in the red module. Genes colored in red are hub genes. Yellow highlighted genes are transcription regulators

leukocyte extravasation through the BBB. Most of these have been implicated in ICH [7]. For example, TLR signaling affects $\mathrm{ICH}$-induced brain injury and outcome [38]. Serum levels of IL-6 and IL-10 increase following ICH [39]. In addition, peroxisome proliferator-activated receptors (PPARs), nuclear hormone receptors that regulate immune/inflammatory responses, have been implicated in $\mathrm{ICH}$ and PPARy agonists improve experimental ICH outcomes [40]. We previously documented differential alternative splicing of PPAR $\gamma$ signaling molecules in ICH [18], which further supports their role in $\mathrm{ICH}$.

Infiltrating neutrophils and monocytes release cytokines, reactive oxygen species (ROS), and matrix metalloproteinases (MMPs), which affect ICH outcomes $[41,42]$. Indeed, the greenyellow module included S100A8 (calcium and zinc-binding protein that regulates the immune response); CCR2 (receptor for monocyte chemoattractant protein-1 which mediates monocyte chemotaxis with CCR2 + inflammatory monocytes regulating hematoma clearance and functional recovery following $\mathrm{ICH}$ ) [7]; PLA2G4A (PLA2G4A deficiency causes platelet dysfunction/ bleeding); CD36 (implicated in cerebral amyloid angiopathy, one of the major causes of $\mathrm{ICH})[43,44]$; F5 (coagulation factor $\mathrm{V}$, a mutation in which causes Factor V Leiden thrombophilia); and MMP9 (matrix metalloproteinase 9 which causes BBB dysfunction resulting in increased capillary permeability and brain edema following ICH $[7,45]$ ).

Of the 14 neutrophil-specific hub genes in the greenyellow module, those with the highest connectivity included MAPK14, WDFY3 (Additional file 1: Figure S8), SULT1B1, DYSF, FLOT2, ANXA3, PYGL, and KLHL2. Other greenyellow hubs were associated with endothelin-1 signaling (PLBD1, MAPK14, CASP4), which is implicated in cerebral vasospasm following subarachnoid hemorrhage [46]. Serum endothelin-1 levels are elevated in ischemic stroke [47] and ICH [48], and endothelin-1 serum levels correlate with $\mathrm{ICH}$ hematoma volumes [48].

Greenyellow hubs were also involved in chemokine signaling (MAPK14, LIMK2), and eicosanoid signaling (PLBD1, ALOX5), which promote inflammation and vascular permeability $[49,50]$. The NLRC4 hub (Additional file 1: Figure S7) forms the NLRC4 inflammasome 


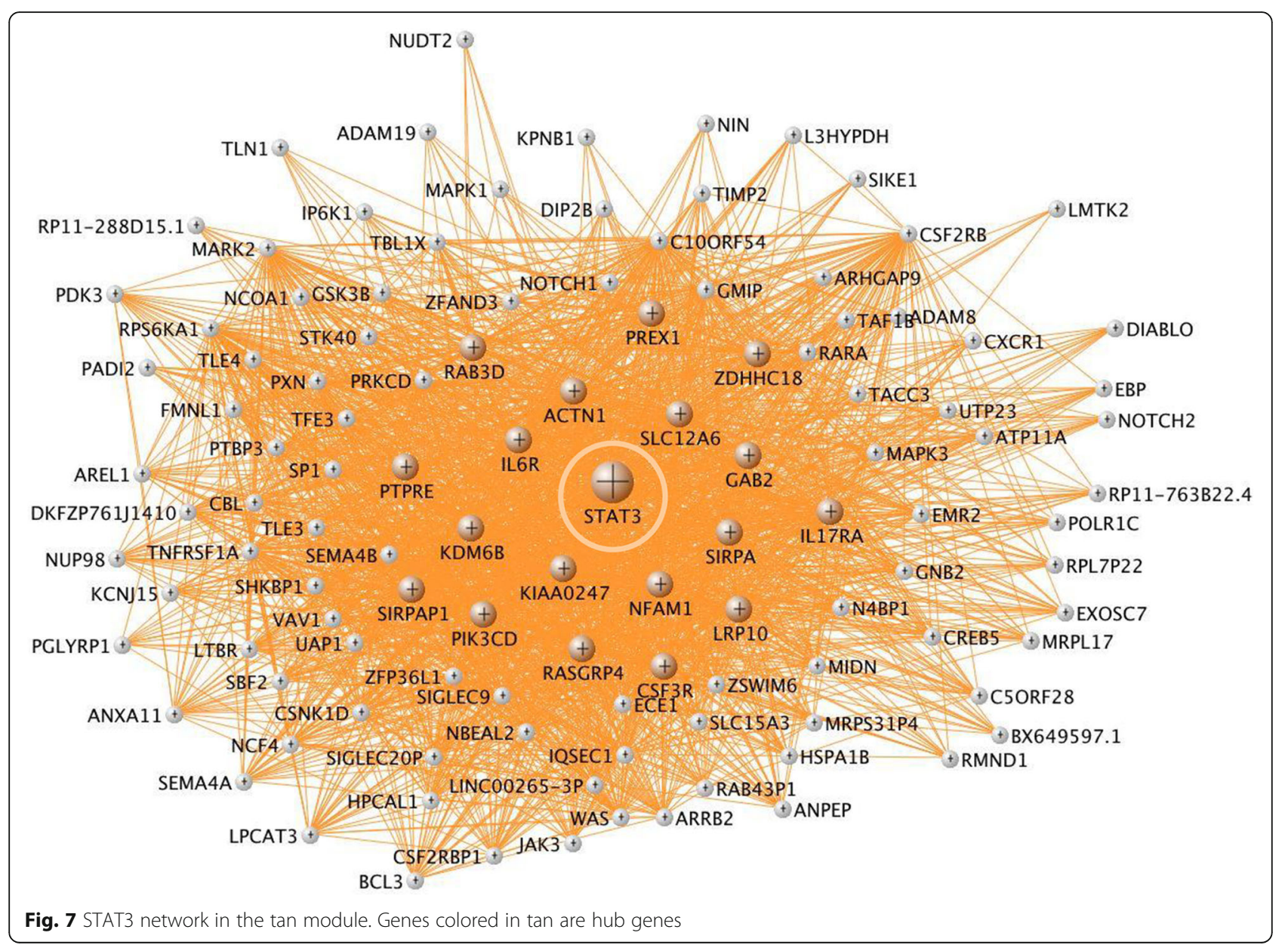

[51, 52]. Inflammasomes, the innate immune system complexes that regulate activation of caspase- 1 and IL-1 to induce inflammation in response to infection and host damage molecules (DAMPs), have been implicated in a variety of inflammatory processes [53] including ICH [54]. In a mouse ICH model, another inflammasome class, the NLRP3 inflammasome, amplified the inflammatory response following $\mathrm{ICH}$, suggesting NLRP3 inflammasome inhibition may reduce the ICH inflammatory response [54, 55]. Our data suggest that NLRC4 type inflammasome response may be important in human ICH, and the NLRC4 hub gene could be a therapeutic target.

There was one microRNA (miRNA) hub in the greenyellow module, miR3614 (Additional file 1: Figure S9). Though little is known about this miRNA, our data show that the miR3614 hub is inter-connected with 40 genes (Additional file 1: Figure S9) enriched in IL-6 and IL-10 signaling (MAPK14, IL1R2), granulocyte adhesion and diapedesis (IL1R2, CXCL16), and phagosome formation (FCAR, CR1) $(p<0.05)$. The data suggest an important inflammatory/immune role for miR3614 in human $\mathrm{ICH}$.
The tan module included immune/inflammatory pathways such as leukocyte extravasation signaling (Additional file 1: Figure S15), production of nitric oxide (NO) and ROS, are all implicated in ICH [7]. Tan module gene members included toll-like receptors TLR1, TLR2, TLR4, and TLR6. The tan module also had 17 neutrophil-specific hub genes including IL6R, GAP2, STAT3, and STX3.

The $\tan$ module was also enriched in Wnt/ $\beta$-catenin signaling which has been implicated in BBB maintenance and breakdown and cell apoptosis [56-58]. Treatment with an inhibitor of GSK-3 $\beta$ (glycogen synthase kinase 3 beta), a key molecule in the Wnt/ $\beta$-catenin signaling pathway, attenuated rtPA-induced hemorrhagic transformation after acute ischemic stroke in rats [59]. Our data revealed significant overrepresentation of Wnt/ $\beta$-catenin signaling pathway genes (11 genes), including GSK-3 $\beta$ (Additional file 1: Figure S17), and support a role for GSK-3 $\beta / \mathrm{Wnt} / \beta$-catenin signaling in human $\mathrm{ICH}$.

The tan module was also associated with growth factor signaling, including HGF, NGF, Neutrophin/TRK, GM-CSF, IGF, FGF, renin-angiotensin, VEGF, and JAK-STAT. ICH patients with high serum levels of 
Table 1 Hub genes in the ICH-significant modules

\begin{tabular}{|c|c|c|c|c|c|c|c|c|}
\hline $\begin{array}{l}\text { Green } \\
\text { Yellow }\end{array}$ & Tan & \multicolumn{2}{|c|}{ Magenta } & \multicolumn{2}{|c|}{ Red } & Sienna3 & Cyan & $\begin{array}{c}\text { DarkOlive } \\
\text { Green }\end{array}$ \\
\hline $\begin{array}{l}\text { ALOX5 } \\
\text { ALPL } \\
\text { ANXA3 } \\
\text { C19orf59 } \\
\text { CASP4 } \\
\text { CDC42EP3 } \\
\text { CR1 } \\
\text { CYSTM1 } \\
\text { DGAT2 } \\
\text { DYSF } \\
\text { ETS2 } \\
\text { FCAR } \\
\text { FLOT2 } \\
\text { GYG1 } \\
\text { KLHL2 } \\
\text { LIMK2 } \\
\text { MAPK14 } \\
\text { MCTP2 } \\
\text { miR3614 } \\
\text { NLRC4 } \\
\text { NUMB } \\
\text { PFKFB3 } \\
\text { PLBD1 } \\
\text { PYGL } \\
\text { RNF24 } \\
\text { RNU6-196P } \\
\text { SRPK1 } \\
\text { SULT1B1 } \\
\text { TRIM25 } \\
\text { WDFY3 } \\
\text { YIPF1 }\end{array}$ & $\begin{array}{l}\text { ACTN1 } \\
\text { C10orf54 } \\
\text { CHST15 } \\
\text { CSF3R } \\
\text { GAB2 } \\
\text { IL17RA } \\
\text { IL6R } \\
\text { ITPRIP } \\
\text { KDM6B } \\
\text { KIAA0247 } \\
\text { LILRA2 } \\
\text { LRP10 } \\
\text { MAP3K3 } \\
\text { MXD1 } \\
\text { NFAM1 } \\
\text { PIK3CD } \\
\text { PREX1 } \\
\text { PTPRE } \\
\text { RAB3D } \\
\text { RASGRP4 } \\
\text { REPS2 } \\
\text { SIRPA } \\
\text { SIRPAP1 } \\
\text { SLC12A6 } \\
\text { SLC6A6 } \\
\text { STAT3 } \\
\text { STX3 } \\
\text { ZDHHC18 }\end{array}$ & $\begin{array}{l}\text { ASCC3 } \\
\text { ATIC } \\
\text { BUB3 } \\
\text { CCDC88C } \\
\text { CD96 } \\
\text { CDKAL1 } \\
\text { CHD6 } \\
\text { DDX24 } \\
\text { DDX47 } \\
\text { DIS3L2 } \\
\text { DOCK10 } \\
\text { EPRS } \\
\text { EVL } \\
\text { FNBP4 } \\
\text { FUBP1 } \\
\text { IARS } \\
\text { ITK } \\
\text { KAT6B } \\
\text { KRIT1 }\end{array}$ & $\begin{array}{l}\text { LCK } \\
\text { LRBA } \\
\text { MRPS30 } \\
\text { NUP205 } \\
\text { OGFOD1 } \\
\text { PHF14 } \\
\text { POLH } \\
\text { PTCD3 } \\
\text { RASGRP1 } \\
\text { RP11-163E9.2 } \\
\text { SEPT1 } \\
\text { SKAP1 } \\
\text { TDP1 } \\
\text { TRAJ36 } \\
\text { TTC3 } \\
\text { TTC3P1 } \\
\text { URI1 } \\
\text { ZZZ3 }\end{array}$ & $\begin{array}{l}\text { AAK1 } \\
\text { AC093838.4 } \\
\text { AMBRA1 } \\
\text { CCDC6 } \\
\text { COG7 } \\
\text { CS } \\
\text { CTB-5212.4 } \\
\text { CTCF } \\
\text { CYFIP2 } \\
\text { DCAF5 } \\
\text { DCAF7 } \\
\text { DIDO1 } \\
\text { ESYT1 } \\
\text { GANAB } \\
\text { GORASP2 } \\
\text { INO80D } \\
\text { MED1 } \\
\text { MLLT10 } \\
\text { MTA2 } \\
\text { MTOR } \\
\text { NUP210 } \\
\text { NUP62 } \\
\text { PPP2R1A } \\
\text { PTBP1 }\end{array}$ & $\begin{array}{l}\text { PUM1 } \\
\text { QRICH1 } \\
\text { R3HDM1 } \\
\text { RASA3 } \\
\text { RBBP6 } \\
\text { REPS1 } \\
\text { RNPS1P1 } \\
\text { RP11-325E14.2 } \\
\text { RP5-961K14.1 } \\
\text { RPRD2 } \\
\text { SEC31A } \\
\text { SEC61A1 } \\
\text { SMARCC2 } \\
\text { SNRNP200 } \\
\text { SOS1 } \\
\text { SRRM1 } \\
\text { SYNRG } \\
\text { TIMM10B } \\
\text { TP53 } \\
\text { TUBB } \\
\text { UBAP2L } \\
\text { VPS11 } \\
\text { WBP11P1 }\end{array}$ & $\begin{array}{l}\text { ANK1 } \\
\text { AP2A1 } \\
\text { ASCC2 } \\
\text { GUCD1 } \\
\text { MAF1 } \\
\text { RNF123 } \\
\text { SLC4A1 }\end{array}$ & $\begin{array}{l}\text { DCAF12 } \\
\text { EPB41 } \\
\text { FAM104A } \\
\text { FAM210B } \\
\text { FAM46C } \\
\text { GSPT1 } \\
\text { MKRN1 } \\
\text { MKRN4P } \\
\text { MKRN5P } \\
\text { MKRN9P } \\
\text { MXI1 } \\
\text { PIP4K2A } \\
\text { RIOK3 } \\
\text { RP11-329A14.1 } \\
\text { RP11-535M15.2 } \\
\text { RP4-655L22.4 } \\
\text { STRADB } \\
\text { STRADBP1 }\end{array}$ & $\begin{array}{l}\text { ANXA1 } \\
\text { ATG3 } \\
\text { ATG3P1 } \\
\text { CAPZA1 } \\
\text { GLRXP3 } \\
\text { MYL12B } \\
\text { RP3-452M16.1 } \\
\text { UBA3 }\end{array}$ \\
\hline
\end{tabular}

growth factors such as vascular endothelial growth factor (VEGF), granulocyte-colony stimulating factor (G-CSF), and angiopoietin 1 had good functional outcome and reduced lesion volume [45]. TGFBR1 (TGF beta receptor 1), a tan module gene, when mutated in humans causes the Loeys-Dietz syndrome that is associated with cerebral aneurysms and arterial dissections [60]. Moreover, TGF- $\beta 1$ promotes recovery after experimental ICH [61]. Modulating JAK-STAT signaling also affects outcomes in experimental ICH [62].

Colony stimulating factor 3 receptor (CSF3R) is a neutrophil-specific Tan hub gene (Additional file 1: Figure S14). It encodes the colony stimulating factor 3 receptor that controls the production, differentiation, and function of granulocytes/neutrophils, and functions in cell surface adhesion or recognition processes. Granulocyte-colony stimulating factor has been investigated as a potential therapeutic target in experimental ICH and shown to improve recovery from neurological deficits, reduce edema and BBB permeability, decrease apoptosis, neutrophil infiltration, and the number of activated microglia/macrophages [45]. A mutation in CSF3R has been implicated in neutrophilic leukemia, characterized by increased neutrophils, and severe bleeding [63]. Several other tan hub genes are involved in growth factor signaling pathways such as PIK3CD,
ACTN1, and STAT3. Signal transducer and activator of transcription 3 (STAT3) (Fig. 7) is involved in ischemic stroke and intracerebral hemorrhage and has been a treatment target for experimental ICH $[64,65]$.

\section{T cell module (magenta module)}

$\mathrm{T}$ lymphocytes are part of the adaptive immune system, and depending upon whether they express CD4 or CD8 surface markers, modulate the immune response or elicit cytotoxicity. T lymphocytes have been detected in perihematomal brain tissue of $\mathrm{ICH}$ patients, and Treg transfer attenuates neurological deficits in experimental ICH [7]. In addition, the circulating $\mathrm{CD} 4^{+} / \mathrm{CD} 8^{+} \mathrm{T}$ lymphocyte ratio has been suggested as a possible predictor of postoperative intracranial pressure and short-term prognosis [66]. Regulatory $\mathrm{T}$ cells ameliorate BBB damage after cerebral ischemia [67] as well as hemorrhagic transformation after tPA administration following ischemic stroke in part by inhibiting CCL2 (monocyte chemoattractant protein 1) and MMP9 [68]. Our previous study showed differential alternatively spliced transcript expression in blood in many $\mathrm{T}$ cell receptor genes [18].

The magenta module was enriched in T cell-specific genes, including $54 \mathrm{~T}$ cell receptor genes (Additional 
Table 2 Selected three relevant hub genes and their relevant functions from each module. $\mathrm{N}$-neutrophil-specific gene, M-monocyte-specific gene, T-T cell-specific gene, EB-erythroblast-specific genes $[43,45,48,54,63,64,71,73,74,81,84,91,92$, $94,102,107-109,116-122]$

\begin{tabular}{|c|c|c|}
\hline & & Tan (Neutrophil Module) \\
\hline $\begin{array}{c}\text { STX3 } \\
(\mathrm{N})\end{array}$ & Synthaxin-3 & $\begin{array}{l}\text { - Modulates Von Willebrand Factor (mediating adhesion of platelets to sites } \\
\text { of vascular damage) [116] }\end{array}$ \\
\hline $\begin{array}{l}\text { STAT3 } \\
(\mathrm{N})\end{array}$ & $\begin{array}{l}\text { Signal transducer } \\
\text { and activator of } \\
\text { transcription } 3\end{array}$ & $\begin{array}{l}\text { - Transcription activator in response to cytokines and growth factors } \\
\text { - Involved in ischemic stroke and hemorrhage and is a focus of investigation } \\
\text { for therapeutic treatments targeting it [64] }\end{array}$ \\
\hline $\begin{array}{l}\text { CSF3R } \\
(\mathrm{N})\end{array}$ & $\begin{array}{l}\text { Colony stimulating } \\
\text { factor } 3 \text { receptor }\end{array}$ & $\begin{array}{l}\text { - receptor for CSF3 (colony stimulating factor 3), a growth factor that } \\
\text { controls the production, differentiation, and function of granulocytes, such } \\
\text { as neutrophils, and may also function in some cell surface adhesion or } \\
\text { recognition processes. } \\
\text { - CSF improves recovery from neurological deficits following ICH, reduce } \\
\text { edema and BBB permeability, decrease apoptosis, neutrophil infiltration, } \\
\text { and the number of activated microglia/macrophages [45]. } \\
\text { - a mutation in CSF3R has been implicated in neutrophilic leukemia, } \\
\text { characterized by drastic elevation of mature neutrophils and associated with } \\
\text { severe bleeding [63] }\end{array}$ \\
\hline \multicolumn{3}{|c|}{ GreenYellow (Neutrophil and Monocyte Module) } \\
\hline $\begin{array}{l}\text { MAPK14 } \\
(\mathrm{N})\end{array}$ & $\begin{array}{l}\text { Mitogen-activate } \\
\text { protein kinase } 14\end{array}$ & $\begin{array}{l}\text { - Activation of MAP kinases are involved in ICH-induced neuronal injury; } \\
\text { MAP kinases' neuroprotective effects mediated by arrestment of microglial } \\
\text { activities [117] } \\
\text { - A part of Endothelin-1 signaling, a pathway involved in vasoconstriction, } \\
\text { and possibly cerebral vasospasm. The endothelin-1 pathway has been } \\
\text { implicated in ICH [48] } \\
\text { - Involved in chemokine signaling }\end{array}$ \\
\hline $\begin{array}{l}\text { WDFY3 } \\
(\mathrm{N})\end{array}$ & $\begin{array}{l}\text { WD repeat and } \\
\text { FYVE domain } \\
\text { containing } 3\end{array}$ & $\begin{array}{l}\text { - A master conductor for aggregate clearance by autophagy, and autophagy } \\
\text { is involved in ICH }[94,102]\end{array}$ \\
\hline NLRC4 & \begin{tabular}{|l|} 
NLR Family CARD \\
Domain Containing 4
\end{tabular} & $\begin{array}{l}\text { - Component of NLRC4-type inflammasome formation with essential role in } \\
\text { innate immune response to tissue damage and other cellular stresses ( } 9 \text { ) } \\
\text { - Another inflammasome class, the NLRP3 inflammasome amplified the } \\
\text { inflammatory response following ICH [54] }\end{array}$ \\
\hline \multicolumn{3}{|r|}{ Magenta (T-cell Module) } \\
\hline IARS & $\begin{array}{l}\text { Isoleucyl-tRNA } \\
\text { Synthetase }\end{array}$ & $\begin{array}{l}\text { - Functions in homeostasis and signaling pathways, including mTOR, IFN-Y } \\
\text { and p53 signaling and have been associated with cardiovascular disease, } \\
\text { autoimmune disorders, inflammation, cancers and neurological disorders } \\
\text { [73]. } \\
\text { - IARS has been implicated in angiogenesis [73], ischemic injury [74]. }\end{array}$ \\
\hline $\begin{array}{l}\text { LCK } \\
(\mathrm{T})\end{array}$ & $\begin{array}{l}\text { LCK Proto- } \\
\text { Oncogene, Src } \\
\text { Family Tyrosine } \\
\text { Kinase }\end{array}$ & $\begin{array}{l}\text { - Specifically expressed in T cells and is a key signaling molecule in the } \\
\text { selection and maturation of developing T-cells, and in T-cell receptor } \\
\text { signaling. } \\
\text { - Transient inhibition of Src Family Kinases, such as FYN improved } \\
\text { cognitive function after ICH or intraventricular thrombin injection in a rat } \\
\text { model [71]. }\end{array}$ \\
\hline $\begin{array}{c}\text { SKAP1 } \\
(\mathrm{T})\end{array}$ & $\begin{array}{c}\text { Src Kinase } \\
\text { Associated } \\
\text { Phosphoprotein } 1\end{array}$ & $\begin{array}{l}\text { - SKAP1 encodes a T-cell adapter protein, promoting adhesion and } \\
\text { degranulation, and playing a critical role in coupling T-cell antigen receptor } \\
\text { stimulation to the activation of integrins. } \\
\text { - Interacts with Src Family Kinases like FYN. } \\
\end{array}$ \\
\hline \multicolumn{3}{|r|}{ Red (NK-cell Module) } \\
\hline MED1 & $\begin{array}{l}\text { Mediator Complex } \\
\text { Subunit } 1\end{array}$ & $\begin{array}{l}\text { - Component of the Mediator Complex, which is a coactivator involved in the } \\
\text { transcription of nearly all RNA polymerase II-dependent genes (transcribing } \\
\text { mRNA, most small nuclear RNA and miRNA) [118]. }\end{array}$ \\
\hline MTOR & \begin{tabular}{|c|} 
Mechanistic Target of \\
Rapamycin Kinase
\end{tabular} & $\begin{array}{l}\text { - Up-regulates protein synthesis by phosphorylating key regulators of mRNA } \\
\text { translation } \\
\text { - Critical regulator of immune responses [81]. } \\
\text { - Pre-clinical models of ICH showed that mTOR Signaling was activated } \\
\text { within } 30 \text { minutes of ICH, predominantly around the hematoma, and } \\
\text { returned to basal levels at } 1 \text { day [84]. } \\
\text { - Rapamycin, an antibiotic that inhibits the activity of mTOR improves } \\
\text { neurobehavioral deficit, increase numbers of Tregs cells, increase IL-10 and } \\
\text { TGF- } \beta \text { and reduce interferon- } \gamma \text { in peripheral blood and in brain [84] }\end{array}$ \\
\hline $\begin{array}{l}\begin{array}{l}\text { snRNP200 } \\
(U 5 \\
\text { Spliceosome } \\
\text { subunit })\end{array} \\
\text { sul }\end{array}$ & $\begin{array}{l}\text { Small Nuclear } \\
\text { Ribonucleoprotein } \\
\text { U5 Subunit } 200\end{array}$ & $\begin{array}{l}\text { - Crucial splicing regulator and is a part of the Spliceosome, which is the } \\
\text { complex that catalyzes pre-mRNA splicing }\end{array}$ \\
\hline \multicolumn{3}{|r|}{ Sienna3 (Erythroblast Module) } \\
\hline $\begin{array}{l}\text { SLC4A1 } \\
\text { (EB) }\end{array}$ & $\begin{array}{l}\text { Solute Carrier Family } \\
4 \text { Member } 1 \text { (Diego } \\
\text { Blood Group) }\end{array}$ & $\begin{array}{l}\text { - An anion exchanger, which is expressed in the erythrocyte plasma } \\
\text { membrane; binds Ankyrin } \\
\text { - Mutations in SLC4A1 cause destabilization of erythrocyte's membrane } \\
\text { leading to hereditary spherocytosis (spherical erythrocytes) }\end{array}$ \\
\hline AP2A1 & $\begin{array}{l}\text { Adaptor Related } \\
\text { Protein Complex } 2 \\
\text { Alpha } 1 \text { Subunit }\end{array}$ & $\begin{array}{l}\text { - Encodes for a subunit of the adaptor protein } 2 \text { (AP-2) complex found in } \\
\text { clathin coated vesicles. } \\
\text { - Part of Clathrin-Mediated Endocytosis Signaling, involved in intracellular } \\
\text { trafficking; evidence for interplay between endocytosis and autophagy has } \\
\text { been suggested [109]. }\end{array}$ \\
\hline $\begin{array}{c}\text { ANK1 } \\
\text { (EB) }\end{array}$ & Ankyrin 1 & $\begin{array}{l}\text { - ANK1 attaches integral membrane proteins to the underlying spectrin-actin } \\
\text { cytoskeleton. } \\
\text { - ANK1 binds to vimentin (implicated in neuroinflammation [91] and in } \\
\text { cerebral amyloid angiopathy, one of the major causes of ICH [43]. }\end{array}$ \\
\hline \multicolumn{3}{|r|}{ Cyan (Erythroblast Module) } \\
\hline PIP4K2A & \begin{tabular}{|c|} 
Phosphatidylinositol- \\
5-Phosphate 4- \\
Kinase Type 2 Alpha
\end{tabular} & $\begin{array}{l}\text { - Involved in regulation of autophagic vacuole assembly; facilitates } \\
\text { autophagy [119]. } \\
\text { - Role in intracellular cholesterol transport [120]. }\end{array}$ \\
\hline MKRN1 & $\begin{array}{l}\text { Makorin Ring Finger } \\
\text { Protein } 1\end{array}$ & $\begin{array}{l}\text { Transcriptional co-regulator and E3 ubiquitin ligase, promoting ubiquitination } \\
\text { and proteasomal degradation. }\end{array}$ \\
\hline EPB41 & $\begin{array}{l}\text { Erythrocyte } \\
\text { Membrane Protein } \\
\text { Band } 4.1\end{array}$ & $\begin{array}{l}\text { Integral part of the erythrocyte's cytoskeleton network; plays a critical role in } \\
\text { erythrocyte's shape and deformity; mutations in EPB41 are associated with } \\
\text { type I elliptocytosis (EL1), hematologic disorder with elliptically shaped } \\
\text { erythrocytes and a variable degree of hemolytic anemia. }\end{array}$ \\
\hline \multicolumn{3}{|r|}{ DarkOliveGreen } \\
\hline UBA3 & $\begin{array}{l}\text { Ubiquitin Like } \\
\text { Modifier Activating } \\
\text { Enzyme } 3\end{array}$ & $\begin{array}{l}\text { - Significance in apoptosis in autophagy [108] [121]. } \\
\text { - Regulation of inflammasome by ubiquitination [107]. }\end{array}$ \\
\hline ATG3 & Autophagy Related 3 & - A critical component of the autophagy machinery [92]. \\
\hline ANXA1 & Annexin 1 & $\begin{array}{l}\text { - Blood brain barrier protection after experimental ICH [122]. } \\
\text { - Anti-inflammatory activity }\end{array}$ \\
\hline
\end{tabular}



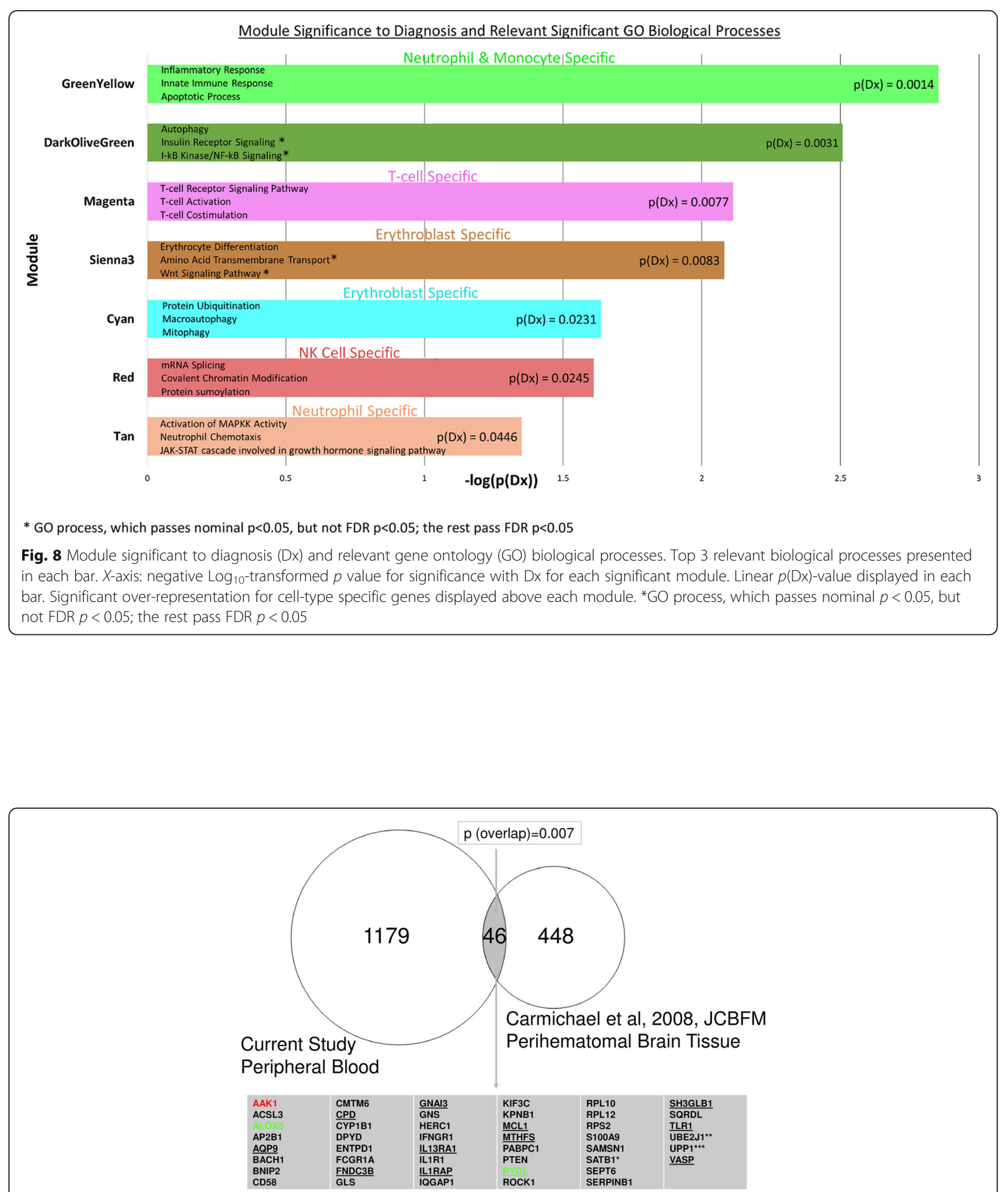

Fig. 9 Overlap between differentially expressed genes in peripheral blood (current study) and perihematomal brain tissue [15] between patients with $\mathrm{ICH}$ and controls. There was significant enrichment $\left(p=6.4 \times 10^{-08}\right)$ of neutrophil-specific genes in the overlap of 46 genes. The underlined genes are neutrophil-specific (based on the HeamAtlas [24]). * SATB1 (SATB Homeobox 1) - T cell-specific based on [25]. ** UBE2J1 (ubiquitin conjugating enzyme E2 J1)—B lymphocyte-specific based on [24]. ** UPP1 (uridine phosphorylase 1) —Monocyte-specific based on [24]. The green yellow genes ALOX5 (arachidonate 5-lipoxygenase) and PYGL (glycogen phosphorylase L) are hub genes in the greenyellow ICH module. The red gene AAK1 (AP2 Associated Kinase) is a hub gene in the red ICH module 
file 1: Figure S16) that were involved in $\mathrm{T}$ cell activation and co-stimulation, CD28 signaling in T helper cells, iCOS-iCOSL signaling in T helper cells, CTLA4 signaling in cytotoxic $\mathrm{T}$ lymphocytes, cytotoxic $\mathrm{T}$ lymphocyte-mediated apoptosis of target cells, cytotoxic $\mathrm{T}$ lymphocyte-mediated apoptosis of target cells, Th1 and Th2 pathways. Our previous study showed that differential expression of a set of alternatively spliced $\mathrm{T}$ cell genes distinguished $\mathrm{ICH}$ from control subjects using a principal components analysis [18]. Of the $69 \mathrm{~T}$ cell receptor transcripts we previously showed were differentially expressed between ICH and control [18], 58 were associated with $\mathrm{ICH}$-associated modules in the current study (44 in magenta, 13 in red, and 1 in tan). This underscores that $\mathrm{T}$ cell receptor genes are not only potential biomarkers, differentially expressed at the gene level and differentially alternatively spliced at the transcript level, but are also operating within specific networks that could affect ICH outcomes.

Additional magenta module molecules included Src family kinases (SFK). We have shown that pharmacological inhibition of SFKs improved outcomes and improved BBB function following experimental $\mathrm{ICH}[69$, 70]. Transient inhibition of SFK family member FYN improved cognitive function after intraventricular hemorrhage or intraventricular thrombin injection in a rat model [71]. In our human data, FYN was a magenta module member (Fig. 5), and one of the magenta hub genes is a SFK called LCK (LCK proto-oncogene, Src family tyrosine kinase) (Fig. 5) which is expressed in $\mathrm{T}$ cells [25]. LCK is involved in the selection and maturation of developing $\mathrm{T}$ cells and in $\mathrm{T}$ cell receptor signaling. Another magenta hub is SKAP1 (Src kinase associated phosphoprotein 1), which interacts with SFKs. SKAP1 encodes a $\mathrm{T}$ cell adapter protein that promotes adhesion and degranulation, which stimulates $\mathrm{T}$ cell antigen receptors to activate integrins.

Another magenta T cell-specific hub was ITK (IL2 inducible $T$ cell kinase). It is a member of the Tec family of non-receptor tyrosine kinases, which regulates the development, function, and differentiation of $\mathrm{T}$ cells and NKT cells (natural killer T cells). Upon T cell receptor activation, a series of phosphorylation events recruit ITK to the cell membrane where it is phosphorylated by LCK. The gene networks of these three hub genes-ITK (Additional file 1: Figure S4), LCK (Fig. 5), and SKAP1were enriched for $\mathrm{T}$ cell receptor signaling and other $\mathrm{T}$ cell pathways.

The magenta hub with the highest intramodular connectivity was IARS (Fig. 3). IARS belongs to the class-I aminoacyl-tRNA synthetase family which catalyzes the attachment of an amino acid to its cognate tRNA as part of the first step of protein synthesis. Besides its enzymatic function, aminoacyl-tRNA synthases also function in homeostasis and signaling pathways, including mTOR, IFN- $\gamma$, and p53 signaling, and have been associated with cardiovascular disease, autoimmune disorders, cancers, and neurological disorders [72]. IARS has been implicated in angiogenesis [73], ischemic injury [74], and inflammation, and the data here suggests IARS might be a novel therapeutic target for $\mathrm{ICH}$.

Sphingosine 1-phosphate receptor 1 (S1PR1), a hub in the magenta module, is connected to 14 genes, notably all of them hubs: CD96, CDKAL1, DDX24, DDX47, DOCK10, EVL, IARS, LCK, MRPS30, OGFOD1, RASGRP1, SEPT1, SKAP1, and TTC3 (Additional file 1: Figure S3). Fingolimod is an FDA-approved S1PR1 immunomodulator treatment for relapsing multiple sclerosis [7, 75]. Fingolimod treatment reduced cell infiltration and brain edema while improving neurological function in experimental $\mathrm{ICH}[36,76]$. In addition, it improved outcomes in one small human ICH trial [77]. Our data suggests that further studies are warranted not only for S1PR1 but also for its sub-network of 14 hub genes (Additional file 1: Figure S3) for their ICH therapeutic potential.

\section{RNA splicing, post-translational and epigenetic modifications module-red module}

The red module was enriched in natural killer (NK) cell-specific genes, cells for which not much is known about their function in $\mathrm{ICH}$. The red module was also enriched for RNA processing, such as regulation of transcription, mRNA splicing via the spliceosome, as well as epigenetic processes such as chromatin remodeling and covalent chromatin modifications. Post-translational modification processes were also represented, including protein SUMOylation which regulates protein structural and functional diversity by covalent attachment of a member of the small ubiquitin-like modifier (SUMO) family of proteins to lysine residues in specific target proteins. Our previous work showed extensive differential alternative splicing in peripheral blood cells following human $\mathrm{ICH}$ [78], thus indicating the importance of transcriptional regulation in human $\mathrm{ICH}$, which is likely immune cell-type specific.

Several red hub genes were involved in regulation of translation as well, which included mechanistic target of rapamycin kinase (mTOR) (Additional file 1: Figure S5). mTOR regulates cellular metabolism, growth, survival, and autophagy [79] in part by upregulating protein synthesis by phosphorylating key regulators of mRNA translation and ribosome synthesis [80]. mTOR also regulates immune responses [81]; controlling the adaptive immune response by promoting differentiation, activation, and function of $\mathrm{T}$ cells, B cells, and antigen-presenting cells [81]; differentiation and function of regulatory and 
effector T cells [82]; and development and activation of NK cells [83]. mTOR signaling is activated around the hematoma within $30 \mathrm{~min}$ of experimental $\mathrm{ICH}$, and returned to baseline by one day [84]. Rapamycin, an antibiotic that inhibits mTOR, improves behavioral deficits, increases regulatory $\mathrm{T}$ cells, increases interleukin-10 and transforming growth factor- $\beta$, and reduces interferon- $\gamma$ both in peripheral blood and brain following experimental $\mathrm{ICH}$ [84]. Our data supports a role for mTOR in human ICH.

Another red module hub gene was a non-coding RNA, small nuclear ribonucleoprotein U5 subunit 200 (SNRNP200) (Fig. 6). SNRNP200 regulates splicing as part of the Spliceosome, which is the complex that catalyzes pre-mRNA splicing. It consists of specialized RNA and small nuclear RNA proteins (snRNPs) U1, U2, U4, U5, and U6, together with 80 other proteins. U5 snRNP contains nine specific proteins and SNRNP200 encodes one of the U5 snRNP-specific proteins. The SNRNP200 network itself contained the hub gene mTOR and 24 out of the 106 genes from the SNRNP200 network were transcriptional regulators (Fig. 6, highlighted), including MED1 (hub), MED14, CTCF (hub), MAML2, SMARCA2, SMARCC1, and SMARCC2 (hub; T cell specific). MAML2 is a transcriptional coactivator for NOTCH proteins [85]. Mutations in the Notch signaling pathway cause heart and vessel disease. Mutations in the $\mathrm{NOTCH} 1$ receptor are associated with cardiac disease, while mutations in NOTCH3 cause cerebral autosomal dominant arteriopathy with subcortical infarcts and leukoencephalopathy (CADASIL), which is a vascular disorder with middle-aged onset, associated with ischemic stroke and microhemorrhages [85]. Mediator complex subunit 1 (MED1) and mediator complex subunit 14 (MED14) are components of the mediator complex, which is a coactivator that regulates transcription of nearly all RNA polymerase II-dependent genes (transcribing mRNA, most small nuclear RNA and miRNA). The mediator complex functions as a bridge to convey information from gene-specific regulatory proteins to the basal RNA polymerase II transcription machinery. SMARCA2, SMARCC1, and SMARCC2 regulate gene transcription by altering the chromatin structure around the target genes. Our findings underscore the importance of transcriptional regulation, alternative splicing, and epigenetic mechanisms in the pathophysiology of ICH.

\section{Erythroblast modules-sienna3 and cyan module}

The sienna3 and cyan modules were enriched in erythroblast-specific genes. Erythroblasts are nucleated red blood cells (NRBC), which are progenitors of the enucleate erythrocytes in peripheral blood. NRBCs do not typically cross the barrier between the bone marrow and the peripheral circulation. They are found in peripheral blood under conditions that increase erythropoietic pressure such as inflammation, massive hemorrhage, or severe hypoxia and are associated with poor prognosis and higher mortality [86, 87]. Elevated NRBC have been observed in cerebral hemorrhage in severely growth-restricted infants [88] and in intraventricular hemorrhage in preterm neonates [89]. NRBC are also observed in some cases of sudden infant death syndrome [90].

The sienna3 module had 25 erythroblast-specific genes, including genes involved in congenital hemolytic anemia (ANK1 (ankyrin 1), EPB42 (erythrocyte membrane protein band 4.2), HK1 (hexokinase 1), SLC4A1 (solute carrier family 4 member 1 (Diego blood group)), and SPTB (spectrin beta, erythrocytic)), hereditary spherocytosis (spherical-shaped erythrocytes) (ANK1, EPB42, SLC4A1, SPTB), anemia (ALAS2 (5'-aminolevulinate synthase 2), ANK1, EPB42, HK1, KLF1 (Kruppel like factor 1), SLC2A1, SLC4A1, SPTB), heme biosynthesis (ALAS2), and heme degradation (BLVRB, biliverdin reductase B). The cyan module had 24 erythroblast-specific genes, including ones involved in an iron homeostasis signaling pathway (ABCB10 (ATP binding cassette subfamily B), FECH (ferrochelatase), HBQ1 (hemoglobin subunit theta 1), TFRC (transferrin receptor), and heme biosynthesis (ALAD (aminolevulinate dehydratase), FECH). The expression of erythroblast-specific genes in peripheral blood suggests erythroblasts are present in blood of patients with ICH.

Of the sienna3 hub genes, SLC4A1 (Additional file 1: Figure S11), ANK1 (Additional file 1: Figure S12), and ring finger protein 123 (RNF123) were erythroblastspecific. SLC4A1 encodes an anion exchanger expressed in the erythrocyte plasma membrane. The $\mathrm{N}$-terminal domain in the cytoplasm is an attachment site for the red cell skeleton by binding ankyrin. SLC4A1 mutations cause destabilization of the erythrocyte's membrane leading to hereditary spherocytosis. ANK1 attaches integral membrane proteins to the underlying spectrin-actin cytoskeleton. ANK1 binds to the erythrocyte membrane protein band 4.2 (EPB42, present in this module) to vimentin which is implicated in neuroinflammation [91] and in cerebral amyloid angiopathy, which is one of the major causes of ICH [43]. ANK1 also links spectrin beta chains (encoded by SPTB, also in this module) to the cytoplasmic domain of SLC4A1 and other exchange proteins.

\section{Autophagy following ICH}

Autophagy involves lysosome-dependent degradation/recycling of cellular components, ranging from proteins to organelles. In macroautophagy, the components are sequestered in a double-membrane-bound organelle, the 
autophagosome, to eventually fuse with lysosomes for digestion by lysosomal hydrolases [92, 93]. The autophagosome is formed by recruitment of about 15 autophagy-related (ATG) proteins and associated proteins. Autophagy plays a fundamental role in homeostasis, cell death, and in the immune/inflammatory response and its regulation [94]. Dysregulation of autophagy has been implicated in cardiovascular diseases [95], neurodegenerative diseases [96-99], ischemic stroke [100], and experimental ICH [101], reviewed in [102]. Autophagy activation and mitophagy (selective degradation of mitochondria) promoted by voltagedependent anion channels has also been associated with neuroprotection against cell death following subarachnoid hemorrhage [103]. Autophagy also occurs following experimental cerebral ischemia [104] and ICH [101, 102]. Iron overload from the hematoma plays a key role in $\mathrm{ICH}$-induced autophagy. Infusion of ferrous iron into rat striatum caused autophagy which was reduced by an iron chelator [101]. Neuronal cell death following TBI correlates with autophagy activation and an autophagic clearance impairment [102].

Autophagy-related biological processes populated several of our human ICH modules. The cyan module was significant for macroautophagy, autophagosome assembly, mitophagy [93] (Fig. 8, Additional file 2: Table S8), and TORC2 signaling which regulates autophagy [105]. Major autophagy genes in this module included WIPI2, a component of the autophagosomal machinery that participates in the recruitment of certain ATG (autophagy-associated) proteins; ATG9A, which organizes the pre-autophagosomal structure/phagophore assembly site; and PTEN-induced putative kinase 1 (PINK1), which is involved in selective autophagy with rare mutations being associated with Parkinson's disease [94].

Autophagy, including mitophagy, plays an important role during erythropoiesis, allowing the proper maturation of red blood cells [106]. The dysfunction of autophagy interferes with the correct erythroid maturation, leading to hematological abnormalities, such as the release of immature red blood cells (erythroblasts) from the bone marrow [106]. In fact, as mentioned above, the presence of circulating erythroblasts in adults reflects increases in erythropoietic activity or failure of the blood filtration mechanism during hematopoietic stress such as inflammation, severe bleeding, hematological malignancy, or severe hypoxia [86].

The cyan module was also enriched in protein ubiquitination pathways which can regulate neuroinflammation [107] and autophagy [108]. This module was also enriched for genes in the NRF2-mediated oxidative stress response pathway, which has been implicated in enhancing the anti-oxidative capacity, phagocytosis, and hematoma clearance following experimental $\mathrm{ICH}$ by modulating microglia function following $\mathrm{ICH}$ [31]. Clathrin-mediated endocytosis signaling was also enriched, which is involved in intracellular trafficking and may link endocytosis to autophagy [109]. Thus, one might consider the cyan module to be related to hematoma clearance, since it is associated with autophagy, endocytosis, protein ubiquitination, and oxidative stress-response pathways.

Another module enriched in autophagy genes was the darkolivegreen module, where regulation of macroautophagy was the most significant biological process. Moreover, the ATG3 (autophagy related 3) (Additional file 1: Figure S10) hub gene in this module is a component of the autophagy machinery. The darkolivegreen module was also enriched for NF-kB signaling that regulates inflammation, notable since there is a bidirectional regulation between inflammation/NF-kB pathway and autophagy [110]. Indeed, autophagy may regulate ICH-induced neuronal damage via NF-kB [111].

Other hub genes in our data that are key players in autophagy or its regulation include WD repeat and FYVE domain containing 3 (WDFY3, Additional file 1: Figure S8), mechanistic target of rapamycin kinase (mTOR, Additional file 1: Figure S5), VPS11 (VPS11, CORVET/HOPS core subunit), and autophagy and beclin 1 regulator 1 (AMBRA1, Additional file 1: Figure S6). Of these, only mTOR has been shown to play a role in ICH [112]. It is notable that AMBRA1 is required for adult neurogenesis [113], which is impaired after experimental ICH [114].

Since autophagy can be a pro-survival or pro-death mechanism, and may be beneficial or detrimental, more studies are needed to elucidate its role(s) in human ICH. Our results point to a role of autophagy in the peripheral blood cells and their response to human $\mathrm{ICH}$.

\section{Other blood cell types}

Though most modules were enriched in cell type-specific genes, pathways associated with other cell types were also represented in these modules. For example, the most overrepresented pathway in the neutrophil gene-enriched module was B cell receptor signaling. Though a minor role of $\mathrm{B}$ cells in $\mathrm{ICH}$-induced brain injury has been suggested [7], our data suggest B cells are involved in the pathophysiology of human $\mathrm{ICH}$. B cells, in addition to producing antibodies, modulate the functions of other immune cells which might be important in $\mathrm{ICH}[115]$.

\section{Blood and brain overlap following human $\mathrm{ICH}$}

There was a significant 46-gene overlap from our human blood study and the genes differentially expressed in human brain following ICH [15]. The 46 overlapping genes showed enrichment for neutrophil-specific genes which may be due to infiltrating neutrophils into perihematomal brain tissue. The 46 genes were involved in 
interleukin 1, 6, 8, and 10 signaling (GNAI3, IL1R1, IL1RAP, ROCK1, IQGAP1, VASP, MCL1), neuroinflammation signaling (GLS, TLR1, IFNGR1, IL1R1), apoptosis (ROCK1, MCL1), PPAR signaling, and leukocyte extravasation signaling (ROCK1, GNAI3, VASP). In addition, three of these blood-brain shared genes (AAK1, ALOX5, and PYGL, Fig. 9) were hub genes in our data. It is plausible they are master regulators in the peripheral immune response and potentially play important role following $\mathrm{ICH}$ in perihematomal brain tissue. Thus, they need to be investigated further both in blood and brain. Treatments targeting the 46 shared genes might be considered a priority since this presumably would target peripheral blood immune cells, blood immune cells in brain, and likely brain immune and non-immune cells.

\section{Limitations}

The results need to be validated in a larger study. In addition, the cell-specific expression of each blood cell type is based on their expression in healthy subjects and their cell-specificity may differ in disease. Investigation of isolated cell types will help delineate the contribution of each cell type to the immune response to $\mathrm{ICH}$. Though a given module may be enriched for genes in a specific cell type, there were always genes from other cell types associated with those modules. The role of any given module or hub gene in $\mathrm{ICH}$ is difficult to discern from the current study but can often be inferred from experimental ICH studies or the literature.

\section{Conclusion}

Our data revealed inflammatory, regulatory, and autophagy modules of co-expressed genes associated with $\mathrm{ICH}$ that were highly enriched with cell-specific genes. This allowed us to identify discrete neutrophil, monocyte, $\mathrm{T}$ cell, natural killer cell, and erythroblast gene modules and hub genes. Many of the modules and hub genes either provide novel $\mathrm{ICH}$ therapeutic targets or provide human data supporting animal findings for already existing targets. The data also revealed a significant overlap between blood and brain gene responses, underscoring the importance of blood-brain interactions in human ICH.

\section{Additional files}

Additional file 1: Figure S1. Soft-thresholding power (A) and connectivity (B). Figure S2. IARS network in the Magenta module. Genes colored in magenta are hub genes. Figure S3. S1PR1 network within the Magenta module. Genes colored in magenta are hub genes. Note all genes in the S1PR1's network are hub genes. Figure S4. ITK network within the Magenta module. Genes colored in magenta are hub genes. Figure S5. mTOR Network in the Red Module. Genes colored in red are hub genes. Figure S6. AMBRA1 Network in the Red Module. Genes colored in red are hub genes. Figure S7. NLRC4 Network in the GreenYellow Module.
Genes colored in green-yellow are hub genes. Figure S8. WDFY3 Network in the GreenYellow Module. Genes colored in green-yellow are hub genes. Figure S9. miR3614 Network in the GreenYellow Module. Genes colored in green-yellow are hub genes. Figure S10. ATG3 Network in the DarkOliveGreen Module. Genes colored in dark green are hub genes. Figure S11. SLC4A1 Network in the Sienna3 Module. Genes colored in brown are hub genes. Figure S12. ANK1 Network in the Sienna3 Module. Genes colored in brown are hub genes. Figure S13. PIP4K2A Network in the Cyan Module. Genes colored in cyan are hub genes. Figure S14. CSF3R Network in the Tan Module. Genes colored in tan are hub genes. Figure S15. Leukocyte Extravasation Signaling Pathway. Genes circled in purple are present in the Tan Module. Figure S16. T cell Receptor Signaling Pathway. Genes circled in purple are present in the Magenta Module. Figure S17. GSK-3 $\beta$ Network in the Tan Module. Genes colored in tan are hub genes. (PDF $4696 \mathrm{~kb}$ )

Additional file 2: Table S1. Subjects' demographic information and clinical characteristics. Table S2. List of all 21,175 genes and their respective modules. Table S3. Hypergeometric probability testing for all $p(\mathrm{Dx})<0.05$ modules to all cell-types studied in this document. Table S4. List of the top $5 \%$ of the most interconnected genes (based on intramodular connectivity - kIN) within each module. Green-highlighted genes are amongst the top $1 \%$. Table S5. IPA canonical pathways for only the hubs within modules with $p(\mathrm{Dx})<0.05$. Pathways in peach color are significant following Benjamini-Hochberg (B-H) correction. Pathways in tan color only following Fisher's test. Table S6. $p$-values for each module with respect to diagnosis (A) and time since event (B). Table S7. IPA canonical pathways for all genes within modules that showed $p(\mathrm{Dx})<0.05$. Pathways in peach color are significant following Benjamini-Hochberg correction. Pathways in tan color - only following Fisher's test. Table S8. DAVID Gene Ontology results for all modules that showed $p(D x)<0.05$. Pathways in peach color are significant following Benjamini-Hochberg correction. Pathways in tan color - only following Fisher's test. Table S9. List of differentially expressed genes (DEGs) and their respective fold-changes for genes amongst the 21,175 gene list (A). List of hub genes from the 1225 DEGs identified and their respective modules (B). IPA canonical pathways of only the list of 1225 DEGs (C). Cell-type involvement on all 1225 DEGs from this study (D). Cell-type involvement on only hub genes within the 1225 DEGs from this study (E). List of DEGs from this study that overlapped with the DEGs identified in Carmichael, et al. [15] (F). Celltype enrichment on 46 DEGs that overlapped between this study and Carmichael's study [15] (G). IPA canonical pathways of only the 46 DEGs that overlapped between this study and Carmichael's study [15] (H). (XLSX $756 \mathrm{~kb})$

\section{Abbreviations}

AAK1AP2: Associated kinase 1; ABCB10: ATP binding cassette subfamily B; ACTN1: Actinin alpha 1; ALAD: Aminolevulinate dehydratase; ALAS2: 5'Aminolevulinate synthase 2; ALOX5: Arachidonate 5-lipoxygenase; AMBRA1: Autophagy nd beclin 1 regulator 1; ANK1: Ankyrin 1;

ANXA3: Annexin A3; APT: Affymetrix power tools; ATG: Autophagy related; ATG3: Autophagy related 3; ATG9A: Autophagy related 9A; BBB: Blood-brain barrier; BLVRB: Biliverdin reductase B; CADASIL: Cerebral autosomal dominant arteriopathy with subcortical infarcts and leukoencephalopathy; CASP4: Caspase 4; CCL2: C-C motif chemokine ligand 2; CCR2: C-C motif chemokine receptor 2; CD28: CD28 molecule; CD36: CD36 molecule; CD96: CD96 molecule; CDKAL1: CDK5 regulatory subunit associated protein 1 Like 1; CR1: Complement C3b/C4b receptor 1 (Knops Blood Group); CSF: Colony stimulating factor; CSF3R: Colony stimulating factor 3 receptor; CT: Computed tomographic; CTCF: CCCTC-binding factor; CTLA4: Cytotoxic T lymphocyte associated protein 4; CTRL: Control subjects; CXCL16: C-X-C motif chemokine ligand 16; DAMP: Damage molecules; DDX24: DEAD-Box Helicase 24; DDX47: DEAD-Box Helicase 47; DEG: Differentially expressed genes; DGAT2: Diacylglycerol O-acyltransferase 2; DOCK10: Dedicator of cytokinesis 10; DYSF: Dysferlin; EPB42: Erythrocyte membrane protein band 4.2; EVL: Enah/Nasp-like; F: Female subjects; F5: Coagulation factor V; FCAR: FC fragment of IgA receptor; FDR: False discovery rate; FECH: Ferrochelatase; FGF: Fibroblast growth factor; FLOT2: Flotillin 2; FYN: FYN proto-oncogene, Src family tyrosine kinase; GAB2: GRB2 associated binding protein 2; GCCN: GC correction; G-CSF: Granulocyte-colony stimulating factor: GLS: Glutaminase; GM-CSF: Granulocyte-macrophage colony-stimulating 
factor; GNAI3: G protein subunit alpha I3; GO: Gene ontology; GSK3ß: Glycogen synthase kinase 3 beta; $\mathrm{HBQ} 1$ : Hemoglobin subunit theta 1; HGF: Hepatocyte growth factor; HK1: Hexokinase 1; HTA: Human transcriptome array; IARS: Isoleucyl-tRNA synthetase; ICH: Intracerebral hemorrhage; iCOS: Inducible co-stimulator; iCOSL: Inducible T cell costimulator ligand; IFNGR1: Interferon gamma receptor 1; IFN-ү: Interferon gamma; IGF: Insulin-like growth factor; IL-1: Interleukin 10; IL-10: Interleukin 10; IL17RA: Interleukin 17 receptor A; IL1R1: Interleukin 1 receptor type 1; IL1R2: Interleukin 1 receptor type 2; IL1RAP: Interleukin 1 receptor accessory protein; IL-27: Interleukin 27; IL-6: Interleukin 6; IL6R: Interleukin 6 receptor; IL8: Interleukin 6; IPA: Ingenuity pathway analysis; IQGAP1: IQ motif containing GTPase activating protein 1; IS: Ischemic stroke; ITK: IL2 inducible T cell kinase; KLF1: Kruppel like factor 1; KLHL2: Kelch like family member 2; LCK: LCK proto-oncogene, Src family tyrosine kinase; LIMK2: LIM domain kinase 2; LRP10: LDL receptor-related protein 10; M: Male subjects; MAML2: Mastermind like transcriptional coactivator 2; MAP K14: Mitogenactivated protein kinase 14; MCL1: MCL1, BCL2 family apoptosis regulator; MED1: Mediator complex subunit 1; MED14: Mediator complex subunit 14; miR3614: MicroRNA 3614; MMP: Matrix metalloproteinase; MMP9: Matrix metalloproteinase 9; MRI: Magnetic resonance imagining; MRPS30: Mitochondrial ribosomal protein S30; mTOR: Mechanistic target of rapamycin kinase; MXD1: MAX dimerization protein 1; NF-KB: Nuclear factor kappa-light-chain-enhancer of activated B cells; NGF: Nerve growth factor; NK: Natural killer; NKT-cells: Natural killer T cells; NLRC4: NLR family CARD domain containing 4; NLRP3: NLR family pyrin domain containing 3; NO: Nitric oxide; NOTCH1: Notch 1; NOTCH3: Notch 3; NRBC: Nucleated red blood cells; NRF2: Nuclear factor, erythroid 2 like 2; NUMB: NUMB, endocytic adaptor protein; OGFOD1: 2-Oxoglutarate and iron-dependent oxygenase domain containing 1; PIK3CD: Phosphatidylinositol-4,5-bisphosphate 3-kinase catalytic subunit delta; PINK1: PTEN-induced putative kinase 1; PIP4K2A: Phosphatidylinositol-5-phosphate 4-kinase type 2 alpha; PKCO: Protein kinase C theta; PLA2G4A: Phospholipase A2 group IVA; PLBD1: Phospholipase B domain containing 1; PPAR: Peroxisome proliferatoractivated receptor; PPARY: Peroxisome proliferator activated receptor gamma; PYGL: Glycogen phosphorylase L; RASGRP1: RAS guanyl releasing protein 1; REML: Restricted maximum likelihood; RNF123: Ring finger protein 123; ROCK1: Rho associated coiled-coil containing Protein kinase 1; ROS: Reactive oxygen species; rtPA: Recombinant tissue plasminogen activator; S100A8: S100 calcium binding protein A8; S1PR1: Sphingosine-1 phosphate receptor 1; SCL2A1: Solute carrier family 2 member 1; SEPT1: Septin 1; SFK: Src family kinases; SKAP1: Src kinase associated phosphoprotein 1; SLC4A1: Solute carrier family 4 member 1 (Diego blood group); SMARCA2: SWI/SNF related, matrix associated, actin dependent regulator of chromatin, subfamily A, member 2; SMARCC1: SWI/SNF related, matrix associated, actin dependent regulator of chromatin subfamily $\mathrm{C}$ member 1; SMARCC2: SWI/SNF related, matrix associated, actin dependent regulator of chromatin subfamily C member 2; SNRNP200: Small nuclear ribonucleoprotein U5 subunit 200; SPTB: Spectrin beta, erythrocytic; SST: Single space transformation; STAT3: Signal transducer and activator of transcription 3; STX3: Syntaxin 3; SULT1B1: Sulfotransferase family 1B member 1; SUMO: Small ubiquitin-like modifier; TDP1: Tyrosyl-DNA phosphodiesterase 1; TFRC: Transferrin receptor; TGFBR1: (TGF beta receptor 1); TGF-

$\beta 1$ : Transforming growth factor beta $1 ;$ Th1: T helper cell $1 ;$ Th2: T helper cell 2; TLR: Toll-like receptor; tPA: Tissue plasminogen activator; TRAJ36: T cell receptor alpha joining 36; TTC3: Tetratricopeptide repeat domain 3; U1 snRNP: U1 spliceosomal RNA; U2 snRNP: U2 spliceosomal RNA; U3 snRNP: U3 spliceosomal RNA; U4 snRNP: U4 spliceosomal RNA; U5 snRNP: U5 spliceosomal RNA; U6 snRNP: U6 spliceosomal RNA; VASP: Vasodilator stimulated phosphoprotein; VEGF: Vascular endothelial growth factor; VPS11: VPS11, CORVET/HOPS core subunit; VRF: Vascular risk factor; WDFY3: WD repeat and FYVE domain containing 3; WGCNA: Weighted correlation network analysis; WIPI2: WD repeat domain, phosphoinositide interacting 2

\section{Acknowledgements}

We appreciate the support of the UC Davis Department of Neurology and the MIND Institute.

\section{Funding}

This study was funded by the NIH NINDS (National Institute of Neurological Disorders and Stroke) (R01NS079153, R01NS075035, R01NS097000 and R01NS101718), and by the American Heart Association (16BGIA27250263).

\section{Availability of data and materials}

The data that support the findings of this study are available from the corresponding author upon a reasonable request.

\section{Authors' contributions}

$B S, F R S$, and BPA designed the study. MD and BS wrote the manuscript. FRS, GJ, BPA, and AY edited the manuscript. MD and BS performed the data analysis and results interpretation. BPA, BK, and AT assisted in data analysis. GJ and FRS oversaw subject selection and diagnosis. MD, BPA, GJ, FH, HH, $B K, D L, X Z, A T, X C, K N, A Y, F R S$, and BS participated in the conduct and discussions of the studies, and reviewed and approved the manuscript.

\section{Ethics approval and consent to participate}

The protocol was approved by the UC Davis and UC San Francisco Institutional Review Boards and the University of Alberta Health Research Ethics Board and adheres to all federal and state regulations related to the protection of human research subjects, including The Common Rule, the principles of The Belmont Report, and Institutional policies and procedures. Written informed consent was obtained from all participants or their proxy.

\section{Consent for publication}

Not applicable.

\section{Competing interests}

The authors declare that they have no competing interests.

\section{Publisher's Note}

Springer Nature remains neutral with regard to jurisdictional claims in published maps and institutional affiliations.

Received: 11 September 2018 Accepted: 12 February 2019

Published online: 05 March 2019

\section{References}

1. Benjamin EJ, Virani SS, Callaway CW, Chamberlain AM, Chang AR, Cheng S, et al. Heart disease and stroke statistics-2018 update: a report from the American Heart Association. Circulation. 2018;137(12):e211-e4.

2. Ikram MA, Wieberdink RG, Koudstaal PJ. International epidemiology of intracerebral hemorrhage. Curr Atheroscler Rep. 2012;14(4):300-6.

3. Wang J, Dore S. Inflammation after intracerebral hemorrhage. J Cereb Blood Flow Metab. 2007;27(5):894-908.

4. Sacco S, Marini C, Toni D, Olivieri L, Carolei A. Incidence and 10-year survival of intracerebral hemorrhage in a population-based registry. Stroke. 2009; 40(2):394-9.

5. Feigin VL, Lawes CM, Bennett DA, Barker-Collo SL, Parag V. Worldwide stroke incidence and early case fatality reported in 56 population-based studies: a systematic review. Lancet Neurol. 2009;8(4):355-69.

6. $\mathrm{Xi} \mathrm{G}$, Strahle J, Hua Y, Keep RF. Progress in translational research on intracerebral hemorrhage: is there an end in sight? Prog Neurobiol. 2014; 115:45-63.

7. Mracsko E, Veltkamp R. Neuroinflammation after intracerebral hemorrhage. Front Cell Neurosci. 2014;8:388.

8. Mracsko E, Javidi E, Na SY, Kahn A, Liesz A, Veltkamp R. Leukocyte invasion of the brain after experimental intracerebral hemorrhage in mice. Stroke. 2014;45(7):2107-14.

9. Aronowski J, Zhao X. Molecular pathophysiology of cerebral hemorrhage: secondary brain injury. Stroke. 2011;42(6):1781-6.

10. Wu J, Hua Y, Keep RF, Schallert T, Hoff JT, Xi G. Oxidative brain injury from extravasated erythrocytes after intracerebral hemorrhage. Brain Res. 2002; 953(1-2):45-52.

11. Ducruet AF, Zacharia BE, Hickman ZL, Grobelny BT, Yeh ML, Sosunov SA, et al. The complement cascade as a therapeutic target in intracerebral hemorrhage. Exp Neurol. 2009;219(2):398-403.

12. Zhang J, Shi K, Li Z, Li M, Han Y, Wang L, et al. Organ- and cell-specific immune responses are associated with the outcomes of intracerebral hemorrhage. FASEB J. 2018;32(1):220-9.

13. Editorial. Neuroimmune communication. Nat Neurosci. 2017;20(2):127.

14. Schnoor M, Alcaide P, Voisin MB, van Buul JD. Crossing the vascular wall: common and unique mechanisms exploited by different leukocyte subsets during extravasation. Mediat Inflamm. 2015;2015:946509. 
15. Carmichael ST, Vespa PM, Saver JL, Coppola G, Geschwind DH, Starkman S, et al. Genomic profiles of damage and protection in human intracerebral hemorrhage. J Cereb Blood Flow Metab. 2008;28(11):1860-75.

16. Yew KS, Cheng E. Acute stroke diagnosis. Am Fam Physician. 2009;80(1):33-40.

17. Dykstra-Aiello C, Jickling GC, Ander BP, Shroff N, Zhan X, Liu D, et al. Altered expression of long noncoding RNAs in blood after ischemic stroke and proximity to putative stroke risk loci. Stroke. 2016;47(12):2896-903.

18. Stamova B, Ander BP, Jickling G, Hamade F, Durocher M, Zhan X, et al. The intracerebral hemorrhage blood transcriptome in humans differs from the ischemic stroke and vascular risk factor control blood transcriptomes. $J$ Cereb Blood Flow Metab. 2018:271678X18769513. https://doi.org/10.1177/ $0271678 \times 18769513$.

19. Langfelder P, Horvath S. WGCNA: an R package for weighted correlation network analysis. BMC Bioinf. 2008;9:559.

20. Zhang B, Horvath S. A general framework for weighted gene co-expression network analysis. Stat Appl Genet Mol Biol. 2005;4:Article17.

21. Langfelder $P$, Zhang B, Horvath S. Defining clusters from a hierarchical cluster tree: the dynamic tree cut package for R. Bioinformatics. 2008;24(5):719-20.

22. Yang Y, Han L, Yuan Y, Li J, Hei N, Liang H. Gene co-expression network analysis reveals common system-level properties of prognostic genes across cancer types. Nat Commun. 2014;5:3231

23. Langfelder P, Mischel PS, Horvath $S$. When is hub gene selection better than standard meta-analysis? PLoS One. 2013;8(4):e61505.

24. Watkins NA, Gusnanto A, de Bono B, De S, Miranda-Saavedra D, Hardie DL, et al. A HaemAtlas: characterizing gene expression in differentiated human blood cells. Blood. 2009;113(19):e1-9.

25. Chtanova T, Newton R, Liu SM, Weininger L, Young TR, Silva DG, et al. Identification of T cell-restricted genes, and signatures for different $T$ cell responses, using a comprehensive collection of microarray datasets. J Immunol. 2005;175(12):7837-47

26. Kramer A, Green J, Pollard J Jr, Tugendreich S. Causal analysis approaches in ingenuity pathway analysis. Bioinformatics. 2014;30(4):523-30.

27. Huang da W, Sherman BT, Lempicki RA. Systematic and integrative analysis of large gene lists using DAVID bioinformatics resources. Nat Protoc. 2009;4(1):44-57.

28. Stamova B, Green PG, Tian Y, Hertz-Picciotto I, Pessah IN, Hansen R, et al. Correlations between gene expression and mercury levels in blood of boys with and without autism. Neurotox Res. 2011;19(1):31-48.

29. Hu Z, Snitkin ES, DeLisi C. VisANT: an integrative framework for networks in systems biology. Brief Bioinform. 2008;9(4):317-25.

30. Miller JA, Horvath S, Geschwind DH. Divergence of human and mouse brain transcriptome highlights Alzheimer disease pathways. Proc Natl Acad Sci U S A. 2010;107(28):12698-703.

31. Zhao X, Sun G, Ting SM, Song S, Zhang J, Edwards NJ, et al. Cleaning up after $\mathrm{ICH}$ : the role of $\mathrm{Nrf} 2$ in modulating microglia function and hematoma clearance. J Neurochem. 2015;133(1):144-52.

32. Castejon OJ, Castellano A, Arismendi GJ, Medina Z. The inflammatory reaction in human traumatic oedematous cerebral cortex. J Submicrosc Cytol Pathol. 2005;37(1):43-52.

33. Garton T, Keep RF, Hua Y, Xi G. CD163, a hemoglobin/haptoglobin scavenger receptor, after intracerebral hemorrhage: functions in microglia/ macrophages versus neurons. Transl Stroke Res. 2017:8(6):612-6.

34. Sheth KN, Rosand J. Targeting the immune system in intracerebral hemorrhage. JAMA Neurol. 2014;71(9):1083-4.

35. Zhao X, Sun G, Zhang H, Ting SM, Song S, Gonzales N, et al. Polymorphonuclear neutrophil in brain parenchyma after experimental intracerebral hemorrhage. Transl Stroke Res. 2014;5(5):554-61.

36. Sun N, Shen $Y$, Han W, Shi K, Wood K, Fu Y, et al. Selective sphingosine-1phosphate receptor 1 modulation attenuates experimental intracerebral hemorrhage. Stroke. 2016;47(7):1899-906.

37. Zhao X, Ting SM, Liu CH, Sun G, Kruzel M, Roy-O'Reilly M, et al. Neutrophil polarization by $\mathrm{IL}-27$ as a therapeutic target for intracerebral hemorrhage. Nat Commun. 2017:8(1):602.

38. Zhou Y, Wang Y, Wang J, Anne Stetler R, Yang QW. Inflammation in intracerebral hemorrhage: from mechanisms to clinical translation. Prog Neurobiol. 2014;115:25-44

39. Dziedzic T, Bartus S, Klimkowicz A, Motyl M, Slowik A, Szczudlik A. Intracerebral hemorrhage triggers interleukin-6 and interleukin-10 release in blood. Stroke. 2002;33(9):2334-5.

40. Zhao XR, Gonzales N, Aronowski J. Pleiotropic role of PPARgamma in intracerebral hemorrhage: an intricate system involving Nrf2, RXR, and NFkappaB. CNS Neurosci Ther. 2015;21(4):357-66.
41. Qu J, Chen $W, H u$ R, Feng $H$. The injury and therapy of reactive oxygen species in intracerebral hemorrhage looking at mitochondria. Oxidative Med Cell Longev. 2016;2016:2592935.

42. Florczak-Rzepka M, Grond-Ginsbach C, Montaner J, Steiner T. Matrix metalloproteinases in human spontaneous intracerebral hemorrhage: an update. Cerebrovasc Dis. 2012;34(4):249-62.

43. Mehndiratta P, Manjila S, Ostergard T, Eisele S, Cohen ML, Sila C, et al. Cerebral amyloid angiopathy-associated intracerebral hemorrhage: pathology and management. Neurosurg Focus. 2012;32(4):E7.

44. Park L, Zhou J, Zhou P, Pistick R, El Jamal S, Younkin L, et al. Innate immunity receptor CD36 promotes cerebral amyloid angiopathy. Proc Natl Acad Sci U S A. 2013;110(8):3089-94.

45. Katsuki $\mathrm{H}$. Exploring neuroprotective drug therapies for intracerebral hemorrhage. J Pharmacol Sci. 2010;114(4):366-78.

46. Laban KG, Vergouwen MD, Dijkhuizen RM, Sena ES, Macleod MR, Rinkel GJ, et al. Effect of endothelin receptor antagonists on clinically relevant outcomes after experimental subarachnoid hemorrhage: a systematic review and meta-analysis. J Cereb Blood Flow Metab. 2015;35(7):1085-9.

47. Estrada V, Tellez MJ, Moya J, Fernandez-Durango R, Egido J, Fernandez Cruz AF. High plasma levels of endothelin-1 and atrial natriuretic peptide in patients with acute ischemic stroke. Am J Hypertens. 1994; 7(12):1085-9.

48. Alioglu Z, Bulbul I, Orem A, Ozmenoglu M, Vanizor B, Boz C. Increased plasma endothelin-1 levels in patients with intracerebral hemorrhage. J Stroke Cerebrovasc Dis. 2000;9(4):176-80.

49. Wahl M, Schilling L. Regulation of cerebral blood flow--a brief review. Acta Neurochir Suppl (Wien). 1993;59:3-10.

50. Soberman RJ, Christmas P. The organization and consequences of eicosanoid signaling. J Clin Invest. 2003;111(8):1107-13.

51. Raghawan AK, Sripada A, Gopinath G, Pushpanjali P, Kumar Y, Radha V, et al. A disease-associated mutant of NLRC4 shows enhanced interaction with SUG1 leading to constitutive FADD-dependent caspase-8 activation and cell death. J Biol Chem. 2017;292(4):1218-30.

52. Freeman L, Guo H, David CN, Brickey WJ, Jha S, Ting JP. NLR members NLRC4 and NLRP3 mediate sterile inflammasome activation in microglia and astrocytes. J Exp Med. 2017;214(5):1351-70.

53. Yao ST, Cao F, Chen JL, Chen W, Fan RM, Li G, et al. NLRP3 is required for complement-mediated caspase- 1 and IL-1 beta activation in ICH. J Mol Neurosci. 2017;61(3):385-95.

54. Ma Q, Chen S, Hu Q, Feng H, Zhang JH, Tang J. NLRP3 inflammasome contributes to inflammation after intracerebral hemorrhage. Ann Neurol. 2014;75(2):209-19.

55. Ren H, Kong Y, Liu Z, Zang D, Yang X, Wood K, et al. Selective NLRP3 (pyrin domain-containing protein 3) inflammasome inhibitor reduces brain injury after intracerebral hemorrhage. Stroke. 2018:49(1):184-92.

56. Liebner S, Plate KH. Differentiation of the brain vasculature: the answer came blowing by the Wnt. J Angiogenes Res. 2010;2:1.

57. Zhou L, Deng L, Chang NB, Dou L, Yang CX. Cell apoptosis and proliferation in rat brains after intracerebral hemorrhage: role of Wnt/beta-catenin signaling pathway. Turk J Med Sci. 2014;44(6):920-7.

58. Chang J, Mancuso MR, Maier C, Liang X, Yuki K, Yang L, et al. Gpr124 is essential for blood-brain barrier integrity in central nervous system disease. Nat Med. 2017;23(4):450-60.

59. Wang W, Li M, Wang Y, Li Q, Deng G, Wan J, et al. GSK-3beta inhibitor TWS1 19 attenuates rtPA-induced hemorrhagic transformation and activates the Wnt/beta-catenin signaling pathway after acute ischemic stroke in rats. Mol Neurobiol. 2016;53(10):7028-36.

60. Akazawa Y, Inaba Y, Hachiya A, Motoki N, Matsuzaki S, Minatoya K, et al. Reversible cerebral vasoconstriction syndrome and posterior reversible encephalopathy syndrome in a boy with Loeys-Dietz syndrome. Am J Med Genet A. 2015;167a(10):2435-9.

61. Taylor RA, Chang CF, Goods BA, Hammond MD, Mac Grory B, Ai Y, et al. TGF-beta1 modulates microglial phenotype and promotes recovery after intracerebral hemorrhage. J Clin Invest. 2017;127(1):280-92

62. Gong L, Manaenko A, Fan R, Huang L, Enkhjargal B, McBride D, et al. Osteopontin attenuates inflammation via JAK2/STAT1 pathway in hyperglycemic rats after intracerebral hemorrhage. Neuropharmacology. 2018:138:160-9.

63. Mitsumori T, Komatsu N, Kirito K. A CSF3R T618I mutation in a patient with chronic neutrophilic leukemia and severe bleeding complications. Intern Med. 2016;55(4):405-7. 
64. Liang Z, Wu G, Fan C, Xu J, Jiang S, Yan X, et al. The emerging role of signal transducer and activator of transcription 3 in cerebral ischemic and hemorrhagic stroke. Prog Neurobiol. 2016;137:1-16.

65. Krafft PR, McBride D, Rolland WB, Lekic T, Flores JJ, Zhang JH. alpha7 nicotinic acetylcholine receptor stimulation attenuates neuroinflammation through JAK2-STAT3 activation in murine models of intracerebral hemorrhage. Biomed Res Int. 2017;2017:8134653.

66. Su W, Gao C, Wang P, Huang J, Qian Y, Guo L, et al. Correlation of circulating $T$ lymphocytes and intracranial hypertension in intracerebral hemorrhage. World Neurosurg. 2017;107:389-95.

67. Li P, Gan Y, Sun BL, Zhang F, Lu B, Gao Y, et al. Adoptive regulatory T-cell therapy protects against cerebral ischemia. Ann Neurol. 2013;74(3):458-71.

68. Mao L, Li P, Zhu W, Cai W, Liu Z, Wang Y, et al. Regulatory T cells ameliorate tissue plasminogen activator-induced brain haemorrhage after stroke. Brain. 2017;140(7):1914-31.

69. Ardizzone TD, Zhan X, Ander BP, Sharp FR. SRC kinase inhibition improves acute outcomes after experimental intracerebral hemorrhage. Stroke. 2007; 38(5):1621-5.

70. Liu DZ, Ander BP, Xu H, Shen Y, Kaur P, Deng W, et al. Blood-brain barrier breakdown and repair by Src after thrombin-induced injury. Ann Neurol. 2010;67(4):526-33.

71. Liu DZ, Waldau B, Ander BP, Zhan X, Stamova B, Jickling GC, et al. Inhibition of Src family kinases improves cognitive function after intraventricular hemorrhage or intraventricular thrombin. J Cereb Blood Flow Metab. 2017; 37(7):2359-67.

72. Guo M, Schimmel P. Essential nontranslational functions of tRNA synthetases. Nat Chem Biol. 2013;9(3):145-53.

73. Castranova D, Davis AE, Lo BD, Miller MF, Paukstelis PJ, Swift MR, et al. Aminoacyl-transfer RNA synthetase deficiency promotes angiogenesis via the unfolded protein response pathway. Arterioscler Thromb Vasc Biol. 2016;36(4):655-62.

74. Kamphuis W, Dijk F, van Soest S, Bergen AA. Global gene expression profiling of ischemic preconditioning in the rat retina. Mol Vis. 2007;13:1020-30.

75. Chiba K. FTY720, a new class of immunomodulator, inhibits lymphocyte egress from secondary lymphoid tissues and thymus by agonistic activity at sphingosine 1-phosphate receptors. Pharmacol Ther. 2005;108(3):308-19.

76. Zhang X, Liu W, Yuan J, Zhu H, Yang Y, Wen Z, et al. T lymphocytes infiltration promotes blood-brain barrier injury after experimental intracerebral hemorrhage. Brain Res. 2017;1670:96-105.

77. Fu Y, Hao J, Zhang N, Ren L, Sun N, Li YJ, et al. Fingolimod for the treatment of intracerebral hemorrhage: a 2-arm proof-of-concept study. JAMA Neurol. 2014;71(9):1092-101.

78. Dykstra-Aiello C, Jickling GC, Ander BP, Zhan X, Liu D, Hull H, et al. Intracerebral hemorrhage and ischemic stroke of different etiologies have distinct alternatively spliced mRNA profiles in the blood: a pilot RNA-seq study. Transl Stroke Res. 2015;6(4):284-9.

79. Saxton RA, Sabatini DM. mTOR signaling in growth, metabolism, and disease. Cell. 2017;168(6):960-76.

80. Showkat M, Beigh MA, Andrabi Kl. mTOR signaling in protein translation regulation: implications in Cancer genesis and therapeutic interventions. Mol Biol Int. 2014;2014:686984.

81. Powell JD, Pollizzi KN, Heikamp EB, Horton MR. Regulation of immune responses by mTOR. Annu Rev Immunol. 2012;30:39-68.

82. Zeng $\mathrm{H}$, Chi $\mathrm{H}$. mTOR signaling in the differentiation and function of regulatory and effector T cells. Curr Opin Immunol. 2017:46:103-11.

83. Ali AK, Nandagopal N, Lee SH. IL-15-PI3K-AKT-mTOR: a critical pathway in the life journey of natural killer cells. Front Immunol. 2015;6:355.

84. Lu Q, Gao L, Huang L, Ruan L, Yang J, Huang W, et al. Inhibition of mammalian target of rapamycin improves neurobehavioral deficit and modulates immune response after intracerebral hemorrhage in rat. J Neuroinflammation. 2014;11:44

85. Penton AL, Leonard LD, Spinner NB. Notch signaling in human development and disease. Semin Cell Dev Biol. 2012;23(4):450-7.

86. Purtle SW, Horkan CM, Moromizato T, Gibbons FK, Christopher KB. Nucleated red blood cells, critical illness survivors and postdischarge outcomes: a cohort study. Crit Care. 2017;21(1):154.

87. Schwartz SO, Stansbury F. Significance of nucleated red blood cells in peripheral blood; analysis of 1,496 cases. J Am Med Assoc. 1954;154(16):1339-40.

88. Steurer MA, Berger TM. Massively elevated nucleated red blood cells and cerebral or pulmonary hemorrhage in severely growth-restricted infants-is there more than coincidence? Neonatology. 2008;94(4):314-9.
89. Green DW, Hendon B, Mimouni FB. Nucleated erythrocytes and intraventricular hemorrhage in preterm neonates. Pediatrics. 1995;96(3 Pt 1):475-8.

90. Cohen MC, Yong CY, Evans C, Hinchliffe R, Zapata-Vazquez RE. Release of erythroblasts to the peripheral blood suggests higher exposure to hypoxia in cases of SIDS with co-sleeping compared to SIDS non-co-sleeping. Forensic Sci Int. 2010;197(1-3):54-8.

91. Jiang SX, Slinn J, Aylsworth A, Hou ST. Vimentin participates in microglia activation and neurotoxicity in cerebral ischemia. J Neurochem. 2012;122(4): 764-74.

92. Dupont N, Nascimbeni AC, Morel E, Codogno P. Molecular mechanisms of noncanonical autophagy. Int Rev Cell Mol Biol. 2017;328:1-23.

93. Yoo SM, Jung YK. A molecular approach to mitophagy and mitochondrial dynamics. Mol Cells. 2018;41(1):18-26.

94. Morel E, Mehrpour M, Botti J, Dupont N, Hamai A, Nascimbeni AC, et al. Autophagy: a druggable process. Annu Rev Pharmacol Toxicol. 2017; 57:375-98.

95. Pan $B$, Zhang $H$, Cui T, Wang $X$. TFEB activation protects against cardiac proteotoxicity via increasing autophagic flux. J Mol Cell Cardiol. 2017;113: $51-62$.

96. Salminen A, Kaarniranta K, Kauppinen A, Ojala J, Haapasalo A, Soininen H, et al. Impaired autophagy and APP processing in Alzheimer's disease: the potential role of Beclin 1 interactome. Prog Neurobiol. 2013;106-107:33-54.

97. Gan-Or Z, Dion PA, Rouleau GA. Genetic perspective on the role of the autophagy-lysosome pathway in Parkinson disease. Autophagy. 2015;11(9): 1443-57.

98. Pan Y, Sun L, Wang J, Fu W, Fu Y, Wang J, et al. STI571 protects neuronal cells from neurotoxic prion protein fragment-induced apoptosis. Neuropharmacology. 2015;93:191-8.

99. Pan B, Yang L, Wang J, Wang Y, Wang J, Zhou X, et al. C-Abl tyrosine kinase mediates neurotoxic prion peptide-induced neuronal apoptosis via regulating mitochondrial homeostasis. Mol Neurobiol. 2014;49(2):1102-16.

100. Wang P, Shao BZ, Deng Z, Chen S, Yue Z, Miao CY. Autophagy in ischemic stroke. Prog Neurobiol. 2018;163-164:98-117.

101. He Y, Wan S, Hua Y, Keep RF, Xi G. Autophagy after experimental intracerebral hemorrhage. J Cereb Blood Flow Metab. 2008;28(5):897-905.

102. Niu M, Dai X, Zou W, Yu X, Teng W, Chen Q, et al. Autophagy, endoplasmic reticulum stress and the unfolded protein response in intracerebral hemorrhage. Transl Neurosci. 2017:8:37-48.

103. Li J, Lu J, Mi Y, Shi Z, Chen C, Riley J, et al. Voltage-dependent anion channels (VDACs) promote mitophagy to protect neuron from death in an early brain injury following a subarachnoid hemorrhage in rats. Brain Res. 2014;1573:74-83.

104. Adhami F, Liao G, Morozov YM, Schloemer A, Schmithorst VJ, Lorenz JN, et al. Cerebral ischemia-hypoxia induces intravascular coagulation and autophagy. Am J Pathol. 2006;169(2):566-83.

105. Vlahakis A, Powers T. A role for TOR complex 2 signaling in promoting autophagy. Autophagy. 2014;10(11):2085-6.

106. Grosso R, Fader CM, Colombo Ml. Autophagy: a necessary event during erythropoiesis. Blood Rev. 2017;31(5):300-5.

107. Bednash JS, Mallampalli RK. Regulation of inflammasomes by ubiquitination. Cell Mol Immunol. 2016;13(6):722-8.

108. Myeku N, Figueiredo-Pereira ME. Dynamics of the degradation of ubiquitinated proteins by proteasomes and autophagy: association with sequestosome 1/p62. J Biol Chem. 2011;286(25):22426-40.

109. Tooze SA, Abada A, Elazar Z. Endocytosis and autophagy: exploitation or cooperation? Cold Spring Harb Perspect Biol. 2014;6(5):a018358.

110. Netea-Maier RT, Plantinga TS, van de Veerdonk FL, Smit JW, Netea MG. Modulation of inflammation by autophagy: consequences for human disease. Autophagy. 2016;12(2):245-60.

111. Shen X, Ma L, Dong W, Wu Q, Gao Y, Luo C, et al. Autophagy regulates intracerebral hemorrhage induced neural damage via apoptosis and NFkappaB pathway. Neurochem Int. 2016;96:100-12.

112. Wang JP, Zhang MY. Role for target of rapamycin (mTOR) signal pathway in regulating neuronal injury after intracerebral hemorrhage. Cell Physiol Biochem. 2017:41(1):145-53.

113. Yazdankhah M, Farioli-Vecchioli S, Tonchev AB, Stoykova A, Cecconi F. The autophagy regulators Ambra1 and Beclin 1 are required for adult neurogenesis in the brain subventricular zone. Cell Death Dis. 2014:5:e1403.

114. Yang Y, Zhang M, Kang X, Jiang C, Zhang H, Wang P, et al. Impaired adult hippocampal neurogenesis and cognitive ability in a mouse model of intrastriatal hemorrhage. Neurosci Lett. 2015;599:133-9. 
115. Seifert HA, Offner $H$. The splenic response to stroke: from rodents to stroke subjects. J Neuroinflammation. 2018;15(1):195.

116. Schillemans M, Karampini E, van den Eshof BL, Gangaev A, Hofman M, van Breevoort D, et al. Weibel-Palade body localized syntaxin-3 modulates Von Willebrand factor secretion from endothelial cells. Arterioscler Thromb Vasc Biol. 2018;38(7):1549-61.

117. Ohnishi M, Katsuki H, Fujimoto S, Takagi M, Kume T, Akaike A. Involvement of thrombin and mitogen-activated protein kinase pathways in hemorrhagic brain injury. Exp Neurol. 2007;206(1):43-52.

118. Allen BL, Taatjes DJ. The mediator complex: a central integrator of transcription. Nat Rev Mol Cell Biol. 2015;16(3):155-66.

119. Lundquist MR, Goncalves MD, Loughran RM, Possik E, Vijayaraghavan T, Yang A, et al. Phosphatidylinositol-5-phosphate 4-kinases regulate cellular lipid metabolism by facilitating autophagy. Mol Cell. 2018;70(3):531-44.e9.

120. Hu A, Zhao XT, Tu H, Xiao T, Fu T, Wang Y, et al. PIP4K2A regulates intracellular cholesterol transport through modulating PI(4,5)P2 homeostasis. J Lipid Res. 2018;59(3):507-14.

121. Cajee UF, Hull R, Ntwasa M. Modification by ubiquitin-like proteins: significance in apoptosis and autophagy pathways. Int J Mol Sci. 2012;13(9): 11804-31.

122. Wang Z, Chen Z, Yang J, Yang Z, Yin J, Zuo G, et al. Identification of two phosphorylation sites essential for annexin A1 in blood-brain barrier protection after experimental intracerebral hemorrhage in rats. J Cereb Blood Flow Metab. 2017;37(7):2509-25.

Ready to submit your research? Choose BMC and benefit from:

- fast, convenient online submission

- thorough peer review by experienced researchers in your field

- rapid publication on acceptance

- support for research data, including large and complex data types

- gold Open Access which fosters wider collaboration and increased citations

- maximum visibility for your research: over $100 \mathrm{M}$ website views per year

At $\mathrm{BMC}$, research is always in progress.

Learn more biomedcentral.com/submissions 